\title{
LA CONTRIBUCIÓN INDUSTRIAL DE 1852 EN LA RIOJA
}

\section{Joaquín Giró}

Varias son las consideraciones de interés que nos han movido a recuperar esta fuente estadística de estudio. La primera y fundamental, es la necesidad de entrelazar las dos fuentes comúnmente utilizadas en historia económica e industrial como son las proporcionadas por Madoz (1842) y la de Giménez Guited (1862). El vacío que se apreciaba entre la publicación de estas dos series estadísticas distorsionaba excesivamente la comprensión sobre la trayectoria industrializadora o desindustrializadora de los pueblos de La Rioja. Otros investigadores ${ }^{1}$ habían observado hace unos años esta necesidad en su ámbito de estudio:

"El interés en trabajar esta fuente radica en su utilidad para definir en un periodo concreto -que en nuestro caso corresponde a una etapa posterior a la Ley de desvinculación de 1841, e inmediatamente anterior a la Ley de desamortización civil de 1855- la distribución de recursos correspondientes a todas las Baleares. Pero también estamos de acuerdo con A.Segura que la posibilidad de localizar esta fuente para el resto de regiones españolas permitiría conseguir una información extraordinaria de la situación de todo el país".

También García Colmenares ${ }^{2}$ ha utilizado recientemente esta fuente para la provincia de Palencia.

Otra consideración de no menor interés que la anterior ha sido su accesibilidad. El historiador D.Francisco Bermejo Martín apuntaba en su trabajo sobre La Diputación Provincial de La Rioja ${ }^{3}$,

"Hemos localizado en los fondos del A.M. de Logroño, encuadernados en un sólo volumen, todos los Suplementos del B.O.P., que, población por población, e individuo por individuo, recogen las cuotas de las contribuciones directas de la provincia para el año 1852. Esta fuente nos posibilita el estudio de la aplicación de la reforma

\footnotetext{
* Universidad de La Rioja

1. I. MOLL, A.ALBERTI, A. MOREY (1993), p. 182.

2. GARCÍA COLMENARES (1996), p. 148.

3. BERMEJO Y DELGADO (1989), p. 108.
} 
tributaria de los moderados a nuestra provincia, y además nos proporciona datos concretos para realizar comparaciones entre los distintos sectores económicos y entre las diferentes comarcas."

Otra consideración que influye en nuestra decisión de explotar los datos proporcionados por esta fuente, tiene que ver con nuestro interés por conocer desde el enfoque regional, la evolución de las diferentes iniciativas industriales que en el subsector lanero se produjeron en La Rioja desde que ésta alcanzó el status de provincia, para contribuir de ese modo a la historiografia nacional sobre la industria textil lanera.

No sólo por obvio, sino porque en definitiva incurre en el tema central de nuestra tesis, tratamos de obtener más datos acerca de quienes constituyeron las élites económicas y políticas y marcaron con sus estrategias el devenir de la provincia durante el siglo XIX.

Nuestro objetivo básico es la presentación y el análisis de las listas de contribuyentes industriales, comerciales y profesionales, dejando de lado las listas de contribuyentes por propiedad territorial, inmuebles y ganadería, a tenor de nuestro interés y sobretodo porque sus datos han sido explotados con acierto por el profesor Bermejo. La información que recogemos son los nombres y apellidos de los contribuyentes acompañados por las utilidades que contribuyen -o industria o profesión que ejercen- acompañados por la cuota anual de contribución para el Tesoro, en cada uno de los municipios riojanos. Al ser una fuente que identifica a los individuos nos permite el cruzamiento con otras tablas y fuentes, permitiéndonos establecer las redes de parentesco, así como la organización de las estructuras de poder local, en lo que interpretamos como reproducción social.

El tema no es nuevo.Algunas de estas listas y, otras parecidas han sido utilizadas y, también ha sido criticado su uso. Listas de mayores contribuyentes, dudosamente útiles para el reconocimiento de la estructura de la propiedad o de los capitales, pero válidas a efectos de reconocimiento de las élites económicas y políticas de la provincia, región o país. Listas procedentes de las Estadísticas de la contribución industrial y de comercio que sugieren las posibles innovaciones y mejoras instrumentales al expresar el utillaje por el que se paga la cuota de contribución, así como de forma indirecta, al variar la cuota sobre producción.

Rosa Congost ${ }^{4}$ dice a propósito de las listas de mayores contribuyentes que a lo largo de la segunda mitad del siglo XIX van apareciendo diversas listas de

"mayores contribuyentes", casi todas con algún carácter electoral, sea porque se trata de los miembros de una junta electoral provincial, sea porque se trata de los personajes elegibles en una contienda electoral. Este marcado color político nos llena de dudas sobre Ía validez y fiabilidad de estas listas, publicadas en los Boletines Oficiales de cacia provincia por las respectivas Administraciones económicas. A estas dudas se añaden otras derivadas del carácter fiscal de las fuentes: es evidente que, también en los años 1855 y 1875 , las leyes tributarias vigentes permitían una gran ocultación. Ahora bien, también es probable que esta ocultación alcanzase grados extremos en los mayores propietarios, que eran los que disponían de los bienes suficientes $y^{\prime}$ cie 'ja influencia politica necesaria para hacerio impunemente. De aqú 
nuestra completa seguridad de que, si bien pueden no estar "todos", todos los personajes que figuran en nuestras listas son grandes propietarios."

Nosotros entendemos que en 1852 se produce igual fenómeno, pero que del mismo modo que apreciamos la falsificación de los datos fiscales y en ocasiones sobre utilidades como es el caso de algunos fabricantes de Munilla, que no especifican su maquinaria, y simplemente declaran utilidades por "artefactos industriales", a sabiendas de que ellos son los principales industriales (si así podíamos distinguir en aquella época) del sector textil, también apreciamos que están todos los mayores contribuyentes, puesto que entre ellos se dirime, según la ordenanza del gobierno moderado, la posibilidad de ser elector y elegido para algún cargo público.

Otro problema que nos acompaña es la falta de documentos que nos permitieran contrastar esta fuente. El profesor Bermejo Martín ${ }^{5}$ nos señala que

"en el fichero antiguo de fondos de la Delegación de Hacienda encontramos una cartulina-ficha con esta titulación: Expedientes para la evaluación de la contribución territorial, año 1847 y varios, Legajo 1517. Nuestras consultas en el A.H.P., donde se guardan en la actualidad estos fondos, han sido infructuosas. Se nos comunicó que estaban los Legajos anterior y posterior, pero no el que nos interesaba. La probabilidad de que este Legajo, 1517, existiera era muy remota, sin embargo cabía la suerte de ser uno de ésos que durante el traslado podían haber perdido el tejuelo, y estar aún sin controlar. Nuestra inquisición posterior ha dado de nuevo resultados negativos."

Cuestión que no nos extraña, puesto que en cierto momento se clasificó con un lacónico "Expurgo". Aun así hemos decidido profundizar en esta fuente documental, sin establecer otra contrastación que la que nos ofrecen otros investigadores para años posteriores.

Del vaciado y ordenación estadística de los datos suministrados por la Contribución industrial de 1852 de la Provincia de Logroño, varios son los cuadros estadísticos que se han podido organizar. Como el fin último persigue la comparación con otras series estadísticas, hemos utilizado a tal fin los datos proporcionados por el Diccionario Geográfico-Estadístico-Histórico de España y sus posesiones de Ultramar de D. Pascual Madoz, que basado en la Matrícula de Calatrava de 1842 se publicó en 1846. Asimismo hemos hecho uso, en un primer momento, de la Guía Fabril e Industrial de España de 1861, publicada en 1862 por D.Francisco Giménez Guited, y que significativamente se ha utilizado con harta frecuencia por los historiadores como fuente comparativa a nivel provincial y nacional, pese a los graves errores que nos permite sospechar, al menos en cuanto al volumen que cita para la provincia de Logroño, por lo que en hemos tomado como fuente alternativa, en un segundo momento, la suministrada para 1863 por Domingo Gallego (Gallego, Germán y Pinilla:1992:155).

En este sentido, nos hemos extendido en el tiempo con otra fuente de un contemporáneo riojano, D.Antonio Tadeo Delgado y Masnata, que en 1876, publica la Memoria sobre el estado de la Agricultura e Industrias Derivadas en la Provincia de Logroño.

5. BERMEJO y DELGADO (1989), p. 108. 
Con estas series estadísticas, mas las informaciones proporcionadas por otros investigadores que han trabajado con datos de la provincia de Logroño, como es el caso de Pablo García Colmenares y Ojeda San Miguel nos hemos decidido a contrastar la fuente objeto de estudio, en el ánimo de contribuir a un mejor conocimiento de la realidad histórica e industrial de La Rioja, y por añadidura a la de España.

Cuadro I. Fábricas y fabricantes de la industria textil riojana

$\begin{array}{lcccc} & 1842 & 1852^{*} & 1861 & 1876 \\ \text { Ezcaray } & 29 & 40 & 13 & \\ \text { Valgañón } & 1 & 3 & 8 & 16 \\ \text { STO.DOMINGO } & 30 & 43 & 21 & \\ \text { Canales } & 4 & 10 & 6 & 9 \\ \text { Pedroso } & 1 & 5 & 5 & \\ \text { NAJERA } & 5 & 15 & 11 & \\ \text { Ortigosa } & 3 & 5 & 8 & \\ \text { Torrecilla } & 9 & 18 & 13 & \\ \text { Villoslada } & 3 & 6 & 8 & \\ \text { Rabanera } & 1 & 1 & 1 & \\ \text { Soto } & 7 & 21 & 27 & \\ \text { TORRECILLA } & 23 & 51 & 57 & \\ \text { Arnedillo } & 2 & 6 & 5 & \\ \text { Enciso } & 2 & 6 & 9 & \\ \text { Munilla } & 5 & 19 & 8 & \\ \text { ARNEDO } & 9 & 31 & 22 & \\ \text { Aguilar } & & 2 & 2 & \\ \text { Cervera } & 4 & 4 & 10 & \\ \text { CERVERA } & 4 & 6 & 12 & \\ \text { TOTAL PARTIDOS } & 71 & 146 & 123 & \\ & & & & \\ & & & & \end{array}$

Fuentes: 1842 (Madoz); 1852 (BOPL); 1861 (Giménez Guited) y 1876 (Delgado y Masnata). $1852^{*}$ (fabricantes). Elaboración Propia.

Para la elaboración de este cuadro hemos utilizado el sistema de organización administrativa de los partidos judiciales, tal y como fueron organizados tras la declaración de la provincia de Logroño en 1833, que Madoz introduce en su Diccionario, así como por la necesidad de buscar el apoyo de los datos de Delgado y Masnata, que siempre se ofrecen a nivel de partido judicial. En el caso de nuestra fuente estadística de 1852, no hemos tenido otra disyuntiva que anotar "fabricantes" en vez de "fábricas", por lo que el dato numérico es muy superior al expresado en la serie de 1842 o de 1861.

De la observación de este cuadro se desprende en primer lugar la primacía de los partidos judiciales de Torrecilla y de Santo Domingo, debido a la importancia de Soto y Torrecilla en el primero y de Ezcaray en el segundo, aunque el partido de Arnedo 
sigue la estela de los primeros, merced al empuje de los fabricantes de Munilla. De cualquier modo, sigue siendo a mitad de siglo Ezcaray, el centro de referencia de la industria textil riojana, tanto por el número de fábricas como por el de fabricantes, si bien es verdad, que los cambio anticipados por Ojeda San Miguel ${ }^{6}$, en 1852 ya se han consumado.Veamos algunos ejemplos significativos sobre aquellas fábricas que a principios de siglo tuvieron un auge industrializador.

Cuadro II. Mayores contribuyentes del Partido de Santo Domingo

$\begin{array}{lllc}\text { PUEBLO } & \text { NOMBRE } & \text { SECTOR PRODUCTIVO CUOTA (rs vellón) } \\ \text { Sto.Domingo } & \text { Duaso, Ramón } & \text { Comercio } & 722 \\ \text { Sto.Domingo } & \text { Sáez, José } & \text { Comercio } & 611 \\ \text { Sto.Domingo } & \text { Solar, Casimiro } & \text { Comercio } & 611 \\ \text { Sto.Domingo } & \text { Martínez Borja,Fco. } & \text { Comercio } & 611 \\ \text { Sto.Domingo } & \text { Pérez, Formerio } & \text { Comercio } & 611 \\ \text { Ezcaray } & \text { Campo, Fermín } & \text { Comercio } & 572 \\ \text { Ezcaray } & \text { Sáez, León } & \text { Comercio } & 515 \\ \text { Sto.Domingo } & \text { Sáenz del Prado, Ramón } & \text { Comercio } & 514 \\ \text { Sto.Domingo } & \text { Martínez, Esteban } & \text { Comercio } & 514 \\ \text { Sto.Domingo } & \text { Bezares, Leona } & \text { Comercio } & 500 \\ \text { Ezcaray } & \text { Barrenechea, Ramón } & \text { Textil } & 435 \\ \text { Ezcaray } & \text { Pérez Gómez, Manuel } & \text { Textil } & 435 \\ \text { Ezcaray } & \text { Hernáinz, Gregorio y Cía. } & \text { Textil } & 360 \\ \text { Ezcaray } & \text { Dumolin, Juan Nicolás } & \text { Textil } & 340 \\ \text { Sto.Domingo } & \text { Sáez Victores, Pedro } & \text { Comercio } & 334 \\ \text { Ezcaray } & \text { Fábrica de sedas } & \text { Textil } & 322 \\ \text { Sto.Domingo } & \text { Sáez Cosca, Felipe } & \text { Comercio } & 305 \\ \text { Sto.Domingo } & \text { Labarga, Dámaso } & \text { Comercio } & 291 \\ \text { Ezcaray } & \text { Hernáinz, José } & \text { Textil } & 289 \\ \text { Ezcaray } & \text { Puig, Casimiro } & \text { Textil } & 287 \\ \text { Sto.Domingo } & \text { González Peñalva, Pedro } & \text { Comercio } & 250 \\ \text { Ezcaray } & \text { Giraro, Lázaro } & \text { Tintorero } & 235 \\ \text { Ezcaray } & \text { Esteban, Félix e hijos } & \text { Tintorero } & 220 \\ & & & \end{array}$

Fuente: BOPL (1852) y Elaboración Propia.

El mayor contribuyente por industrial, el Excmo. Sr. D. Ramón Barrenechea, es nieto del conocido e importante ganadero D.José Vicente Barrenechea, dueño de una "Real Fábrica de Paños", que si en 1824 contaba con un molino, un batán, edificio de tintes y relave de lanas, y todo el surtido de cardar e hilar, además de otras máquinas,

6. OJEDA SAN MIGUEL (1993).

7. OJEDA SAN MIGUEL (1993), pp. 102 y 103. 
en 1852 todavía parece mantener con pujanza (cuatro cardas, dos tundosas, cuatro telares, un batán, ocho hilanderos de sesenta husos cada uno y una prensa común). Pariente suyo, D.Francisco Barrenechea, fué Diputado a Cortes en los años del Sexenio (1868-1873).

Manuel Pérez Gómez, el otro mayor contribuyente por industrial, es el socio de la "Fábrica de Gonzalo", que se unió en 1829 a Toribio Gonzalo, fabricante preocupado por la introducción de nueva maquinaria ${ }^{8}$, y que si bien mantuvieron dicha sociedad al menos hasta $1843^{\circ}$, en 1852 observamos que han desaparecido de la relación de fabricantes los hermanos Gonzalo, quedando como único industrial Manuel Pérez Gómez (cuatro cardas, dos tundosas, seis telares, un batán y ocho hilanderos de sesenta husos).

La "Fábrica de San Miguel" que en 1840 está formada por la Compañía de D.Gregorio Hernáinz, Francisco y León Perujo, sabemos ${ }^{10}$ que continuó en la década de los sesenta; y que la iniciativa de León Perujo, a tenor de la demanda de productos férricos para la construcción y reparación de maquinaria textil, le llevó a organizar una ferrería en la aldea de Azárrulla, en la que llegó a instalar, los en su tiempo, revolucionarios Altos Hornos. Quizás sea debido a ésta especialización industrial el motivo de que en la lista de mayores contribuyentes por industrial aparezca "Gregorio Hernáinz y Compañía" como el tercer mayor contribuyente con una cuota de 360 rs. (por sus tres cardas, tres tundosas, un batán y nueve hílanderos de sesenta husos); ahora bien, también aparece él solo con una cuota de 43 rs., por dos telares, del mismo modo que León Perujo y Francisco Perujo con dos y tres telares respectivamente, e igual carga contributiva; del mismo grupo familiar aparece José Hernáinz con una cuota de 289 rs.(sexto mayor contribuyente por industrial), por una serie de artefactos industriales (cuatro cardas, una tundosa, dos telares y ocho hilanderos de sesenta husos), y Pedro Hernáinz que como tintorero de fábrica de tejidos tiene una cuota de 192 rs.

La "Real Fábrica", de la que Madoz nos cuenta que "en el día se halla muy reducida y casi cerrada"; diez años después, en 1852, aparece como Fábrica de sedas con una maquinaria novedosa, como son los "dos tornos movidos por agua para retorcer la seda, de sesenta anillos, seis telares para pañuelería de vara de ancho, un telar para terciopelo, tres telares para tafetanes, un tinte y una oficina de tres mesas para pintar a mano", aunque si atendemos las pesquisas de Ojeda San Miguel" "las señales de esta Real Fábrica desaparecen de los documentos a partir de los años sesenta".

Felipe Herrán, hijo de Casimiro Herrán, al que su padre nombró director de los tintes de su establecimiento "Fábrica del Río Glera" ${ }^{12}$, se encuentra en el puesto dieciocho de esta particular escala de mayores contribuyentes con 166 rs., aspecto que no deja duda sobre el hecho de que la fábrica pasó a manos de su hermana Estefanía, casada con el técnico textil francés Alejandro Alemán ${ }^{13}$, ya que al observar el utillaje contributivo (dos cardas, una tercera parte de una prensa, cuatro telares y dos hilanderos

\footnotetext{
8. OJEDA SAN MIGUEL (1993), p. 103.

9. OJEDA SAN MIGUEL (1993), p. 104.

10. OJEDA SAN MIGUEL (1993), pp. 105 y 106.

11. OJEDA SAN MIGUEL (1993), p. 102.

12. OJEDA SAN MIGUEL (1989), p. 39.

13. OJEDA SAN MIGUEL (1993), p. 105.
} 
de sesenta husos), encontramos que la tercera parte de una prensa está en manos de Felipe Herrán, otra tercera parte en manos de Pablo Alemán y el último tercio en manos de Casimiro Puig, séptimo máximo contribuyente con 287 rs. por una industria consistente en dos cardas, una tundosa, tercera parte de una prensa y dos hilanderos de 60 husos. Sabemos ${ }^{14}$ que Casimiro Puig tenía, además, subarrendados dos batanes.

Felipe Herrán fué repuesto como Diputado Provincial en 1854, durante el Bienio Progresista, por el partido judicial de Santo Domingo, como lo había sido en la Diputación de 1841.

Pablo Alemán, cuyo apellido es de ascendencia francesa por su relación de parentesco con Alejandro Alemán, maquinista francés, casado con Estefanía Herrán, que en 1852 tan sólo tenía una cuota directa de 76 rs. (dos cardas, una tundosa, tercera parte de prensa, siete telares y dos tornos de sesenta husos). En los siguientes años ${ }^{15}$ irá progresando hasta

"situarse en 1865 en el primer lugar de la Lista de los 50 mayores contribuyentes por Industria fabril y manufacturera que votan en la Junta Provincial de Agricultura, Industria y Comercio. Como muestra sírvanos estas cifras: en 1860 ocupa el lugar 14 dentro de los cincuenta con 955,22 rs.; en 1861 asciende hasta el séptimo con $1.538,29$ rs.; dos años más tarde está ya a la cabeza de los cincuenta mayores contribuyentes de la provincia de este sector con 3.150 rs., puesto que sigue ocupando a finales del año 1865, con 420 escudos (unos 4.200 rs.). La calificación de "fabricante de cardas» dada en las «Listas de Electores para Diputados a Cortes ultimadas en 15 de Noviembre de 1865", en la población de Ezcaray, con una cuota de contribución de 278,200 escudos puede servirnos como mera hipótesis para aclararnos este rápido ascenso."

Pablo Alemán se encuadrará en la Junta Directiva del Partido Democrático de Ezcaray, que apoya al Gobierno Provisional establecido en 1868 y cuya tendencia es de corte republicano ${ }^{16}$.

Podemos concluir respecto a Ezcaray que, del gran número de fabricantes que tienen una cuota de contribución industrial (aproximadamente cuarenta), tan sólo son 25 los que disponen de una estructura industrial completa como para entender la fabricación textil, es decir, empresas de ciclo integral (hilado, tisaje o ambas), y no empresas de fase ${ }^{17}$, perteneciendo el resto a lo que Ojeda ${ }^{18}$ denomina la Fábrica Popular, es decir, pequeños productores de carácter artesanal, donde se dan algunas de las operaciones de la fabricación textil a pequeña escala.

Este número de 25 fabricantes con proceso fabril completo, está más acorde con los datos ofrecidos por Madoz y Giménez Guited (29 y 13 fábricas respectivamente), de lo que podemos deducir que la tendencia del principal centro textil riojano a lo largo del siglo XIX está encaminada hacia su lenta pero firme desaparición.

14. OJEDA SAN MIGUEL (1993), p. 107.

15. BERMEJO MARTÍN (1989), p. 177.

16. BERMEJO MARTÍN (1989), p. 177.

17. BENAUL BERENGUER (1995), p. 217

18. OJEDA SAN MIGUEL (1993), p. 107. 
Otro aspecto significativo que se desprende de la lectura de la Matrícula de contribuyentes de la villa de Ezcaray, aunque también ocurre en la vecina localidad de Ojacastro, y significativamente no aparece en ninguna otra localidad de la provincia, es la participación en algunos de los artefactos industriales (empresas de fase). Si ya Ojeda ${ }^{19}$ señala que los protocolos notariales durante este periodo de los años cuarenta, están plagados de escrituras de arriendo, nosotros hemos acotado hasta 21 fabricantes (la mitad mas uno del total) que comparten algún o varios artefactos; es decir, en 1852 , las estrategias hereditarias de los fabricantes de principios de siglo han desembocado en una reparto del capital industrial que en nada favorecerá la necesaria capitalización financiera, para la modernización de tan dinámica industria. Sobre dicha hipótesis basamos nuestro trabajo sobre la formación de la burguesía industrial riojana y pensamos que de hecho resulta significativo el auge que tomarán las localidades del partido judicial de Arnedo frente a la decadencia y práctica desaparición de la industria de Ezcaray, Valgañón y Ojacastro, en el partido de Santo Domingo.

Cuadro II. Mayores contribuyentes del partido de Torrecilla

$\begin{array}{llll}\text { San Román } & \text { Bermejo, Pedro } & \text { Tratante lanas } & 665 \\ \text { Torrecilla } & \text { Barrón, Vicente } & \text { Molino Chocolate } & 572 \\ \text { Villoslada } & \text { Sánchez, Isidro } & \text { Textil } & 544 \\ \text { Torrecilla } & \text { Escolar, Isidoro } & \text { Comercio } & 444 \\ \text { Torrecilla } & \text { Soriano, Casimiro } & \text { Comercio } & 444 \\ \text { Torrecilla } & \text { Pinillos, Isidoro } & \text { Comercio } & 444 \\ \text { Torrecilla } & \text { Escolar, Francisco } & \text { Comercio } & 444 \\ \text { Torrecilla } & \text { González, Marcos } & \text { Comercio } & 444 \\ \text { Soto } & \text { González, Fermín } & \text { Textil } & 437 \\ \text { Ortigosa } & \text { Pinillos, Cipriano } & \text { Comercio } & 432 \\ \text { Torrecilla } & \text { García, Baltasara } & \text { Textil } & 426 \\ \text { Soto } & \text { Ruiz, Francisca } & \text { Textil } & 420 \\ \text { Soto } & \text { Domínguez, Remigio } & \text { Textil } & 419 \\ \text { Soto } & \text { Vallejo, Fco.Luis } & \text { Textil } & 322 \\ \text { Soto } & \text { Elías Benito, Miguel } & \text { Textil } & 271 \\ \text { Soto } & \text { Tejada, Melitón } & \text { Textil } & 237 \\ \text { Torrecilla } & \text { Labiano, Eleuterio } & \text { Textil } & 235 \\ \text { Torrecilla } & \text { González del Río, Manuel } & \text { Tintes } & 206 \\ \text { Torrecilla } & \text { Sáez Díez, Fausto } & \text { Tintes } & 206 \\ \text { Torrecilla } & \text { Sorzano, Juan Manuel } & \text { Tintes } & 206 \\ \text { Soto } & \text { Herreros, Manuel } & \text { Tintes } & 204 \\ \text { Ortigosa } & \text { Labarta, Pedro } & \text { Tintorero } & 200\end{array}$

Fuente: BOPL (1852) y Elaboración Propia

19. OJEDA SAN MIGUEL (1993), p. 107. 
Siguiendo con la observación de nuestro cuadro sobre fábricas y fabricantes habíamos concluído la primacía de los partidos judiciales de Torrecilla y Santo Domingo, y si este último lo debía al auge de las fábricas de Ezcaray, el de Torrecilla lo debía a las fábricas de la capital del partido, Torrecilla de Cameros y en el otro valle a las de Soto de Cameros. Torrecilla es un ejemplo de la toma del poder local y la sustitución de la aristocracia ganadera en beneficio de la burguesía emergente. Moreno Fernánde $z^{20}$, da una serie de ejemplos de la oligarquía de Torrecilla, sobre los abusos cometidos en las enajenaciones de terrenos comunales:

-"Entre 1814 y 1844 se enajenaron muchos terrenos de pequeño tamaño, en teoría para apoyar y potenciar las actividades industriales textiles en el pueblo. El proceso era siempre el mismo: se solicitaba una suerte de terreno para edificar o para ampliar un establecimiento industrial, alegando los beneficios que reportaría al común, el ayuntamiento lo concedía inmediatamente, se tasaba el terreno y se procedía a su venta por el precio establecido"-. El resultado era que el fabricante una vez obtenido el terreno no lo destinaba a ningún fin industrial. De este modo, los notables y económicamente más fuertes, en connivencia, cuando no mediante la suplantación, del poder local, -"utilizaron la vía de apoyarse en los bienes comunes como instrumento para escapar a la recesión, o más sencillamente, para satisfacer sus intereses económicos. La excusa de aminorar las necesidades del municipio sirvió de coartada para numerosos negocios privados que escamoteaban bienes de titularidad y uso públicos".

Así pues, no hay duda que la intencionalidad última de estimar Torrecilla como un gran centro industrial, no era sino un medio para acceder a otros intereses de carácter especulativo y sobre todo de acceso a los centros de poder.

Tal y como hemos hecho en Ezcaray, hemos podido determinar que de los dieciocho inscritos en la Matrícula de 1852 con industria textil, tan sólo siete mantienen una estructura de fábrica de ciclo integral, cuatro están inscritos por sostener un batán, otros cuatro por un tinte y tres por una prensa y una tundosa o una sola tundosa.

Siguiendo los datos aportados por Madoz, de las nueve fábricas existentes en $\mathbf{1 8 4 2 ,}$ diez años después éstas se han reducido a siete. De estas siete, sólo una, la de Baltasara García, tiene una cuota de contribución industrial alta ( 426 rs.) y es la tercera en el listado por industrial de este partido judicial. Los otros seis fabricantes tienen cuotas entre 113 y 136 rs. ocupando los puestos 18 a 25 del listado de mayores contribuyentes, aunque si sumáramos su participación contributiva o la de sus parientes por la posesión de tintes obtendrían un puesto superior hasta situarse en los puestos sexto y siguientes. Claro está, sin introducir en la competencia de mayores contribuyentes a otras industrias que no aparecen el cuadro III como la Fábrica de naipes y papel de Manuel María Vallejo (830 rs.), y la fábrica de papel de Sorzano y Tejada (258 rs.), o la que si aparece como el molino de chocolate de Vicente Barrón (572 rs.).

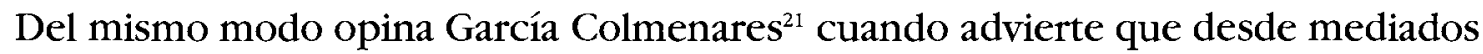
de siglo la estructura industrial es bien escasa, pequeños fabricantes, de los que solamente tienen sistema de fábrica, de reducidas dimensiones, unos pocos.

20. MORENO FERNÁNDEZ (1994), p. 78.

21. GARCÍA DE COLMENARES (1996). Comunicación presentada en el Curso de "Historia Económica". Fundación Duques de Soria. Soria, julio de 1996. Citado por cortesía del autor. 
Soto de Cameros, cabeza industrial y comercial del Camero Viejo muestra un mayor número de fabricantes, incluso si atendemos a las cifras que indica Giménez Guited para 1861, parece que crece el número de establecimientos fabriles. Sin embargo, de los 21 fabricantes o industriales textiles que tienen una cuota fiscal en 1852, tan sólo son ocho los que realmente disponen de la estructura fabril completa o de ciclo integral. De entre estos ocho destaca Fermín González, quien declara, tres telares, dos bancas, tres tornos, tundidora, batán de rueda y mazo y tinte, todo bajo un local (437 rs. y segundo máximo contribuyente de este partido judicial); siendo el único que advierte que todo su utillaje se encuentra en un mismo local. Ahora bien, volvemos a insistir en la discrecionalidad de las listas de mayores contribuyentes. Habría que conocer la trayectoria personal de cada grupo familiar industrial para reconocer la verdad de algunas situaciones fiscales que se desprenden de una lectura somera de estas matriculas de contribución industrial. Por ejemplo, Francisca Ruiz ( 420 rs. y cuarta mayor contribuyente) con seis telares, dos bancas, tres tornos, un tinte y una tundidora, tiene un hermano Gregorio Ruiz, cuya profesión es la de mercader con tienda de chocolate ( 170 rs.) y una hermana Cándida Ruiz cuya industria es un molino harinero de presa y cauce que muele de seis a nueve meses al año $(57 \mathrm{rs}$.). Hay que advertir que Soto es quizás uno de los pueblos modélicos al reconvertir sus numerosos batanes en molinos (Los trece batanes que señala Madoz, son sólo siete en 1852, diez años después). La combinación industria textil, molinería y lonjas o tiendas de chocolate va a ser una constante de estos años de formación de capitales. En otras ocasiones van a ser, además de los molinos el ejercicio del comercio a través de la profesión de mercader, quien determine la diversión de actividades productivas de los grupos familiares. Por ejemplo, volviendo al mayor contribuyente de Soto, por su industria textil, Fermín González, éste declara asimismo utilidades como mercader de géneros de lana o algodón e hilo al por menor y en ambulancia ( $411 \mathrm{rs.)}$ y tiene además un molino que muele cuatro meses al año (36 rs.). Hermano de Fermín, Tomás González, declara poseer dos telares en Soto de Cameros (42 rs.), pero es que en Canales de la Sierra (partido judicial de Nájera), dice poseer una fábrica de paños, de dos cardas movidas por agua, 180 husos, dos telares anchos y una tundosa (169 rs.). Es decir, la estructura de grupo familiar se mantiene con mayor o menor diversificación en sus actividades, de tal modo que, hombres preclaros de la burguesía industrial, encontrarán en la reunión de ese patrimonio familiar el medio de acceder a la necesaria capitalización, y el instrumento que adoptarán será el de las expectativas matrimoniales y las estrategias hereditarias. Un ejemplo más sobre lo que acabamos de apuntar: los hermanos Vallejo de Soto de Cameros.

Francisco Luis Vallejo declara dos bancas, dos tornos, un tinte y un batán (322 rs.), mientras su hermano Casimiro Vallejo dice poseer un batán de rueda y mazo (51 rs.). Francisco Luis tiene además en explotación un molino que muele más de seis meses al año (57 rs.). Cerrando el grupo industrial de los Vallejo está Santiago, cuya actividad es la de mercader de lana, algodón e hilo, al por menor y en ambulancia (411 rs).

No podemos olvidar que los pueblos que tradicionalmente han sido pasto de verano de las cabañas trashumantes, han dedicado una parte de sus esfuerzos demográficos, cuando llegaba la parada invernal, a salir en arriería y dedicarse al comercio desde Galicia hasta Andalucía sin olvidar el periplo americano. 
Cuadro IV. Mayores contribuyentes del partido de Arnedo

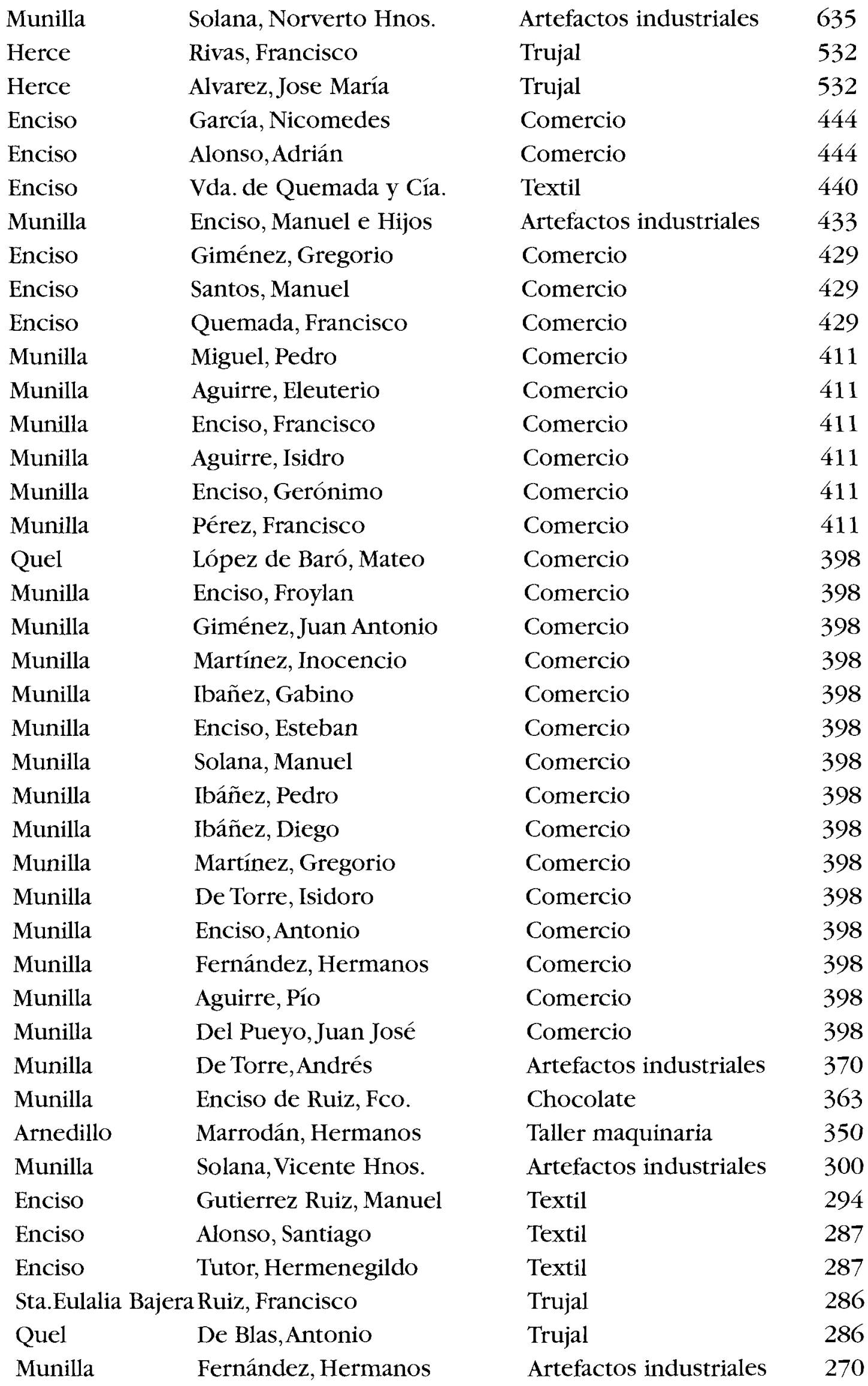




$\begin{array}{llll}\text { Autol } & \text { Sáenz Inestrillas, Francisco } & \text { Trujal } & 269 \\ \text { Autol } & \text { Marqués de Fontellas } & \text { Trujal } & 269 \\ \text { Autol } & \text { Martínez Zulaica, José } & \text { Trujal } & 269 \\ \text { Munilla } & \text { Tutor, Hermenegildo } & \text { Tratante lanas } & 266 \\ \text { Préjano } & \text { Ruiz Gordejuela, Benito } & \text { Trujal } & 260 \\ \text { Arnedillo } & \text { Iñiguez, José } & \text { Trujal } & 233 \\ \text { Arnedillo } & \text { Pozo, Gerónimo } & \text { Trujal } & 233 \\ \text { Arnedillo } & \text { Marrodán, Hermanos } & \text { Chocolate } & 233 \\ \text { Arnedillo } & \text { Rubio, Clemente } & \text { Tratante lanas } & 233 \\ \text { Quel } & \text { De Blas, Antonio } & \text { Aguardiente } & 229 \\ \text { Quel } & \text { Escalona, Francisco } & \text { Aguardiente } & 229 \\ \text { Quel } & \text { Cuadra, Jose María } & \text { Aguardiente } & 229 \\ \text { Quel } & \text { Calatayud, Manuel } & \text { Aguardiente } & 229 \\ \text { Munilla } & \text { Del Pueyo, Gaspar } & \text { Artefactos industriales } & 227\end{array}$

Fuente: BOPL (1852) y Elaboración Propia

Siguiendo en orden descendente, el tercer partido judicial con mayor número de fabricantes es el de Arnedo donde destacan las localidades de Munilla y Enciso, auténticos núcleos fabriles, con un dinamismo superior a cualquier otra localidad incluída la de Ezcaray. Munilla en la Matrícula de 1852 no nos permite reconocer todo el utillaje de que dispone, ya que al menos 14 contribuyentes se expresan como poseedores de artefactos industriales. En cualquier caso hemos determinado que de los 19 industriales o fabricantes textiles, tan sólo nueve poseen lo que hemos denominado estructura fabril completa, cantidad más próxima a la ofrecida por $\mathrm{Madoz}^{22}$ o Giménez Guited (cinco y ocho respectivamente). Mientras, en la localidad de Enciso, la proporción estimada es de cinco de los seis fabricantes declarados. Dicho esto, conviene que nos detengamos en quiénes son estos poseedores de una estructura fabril de ciclo integral, tal y como hemos resuelto en las demás localidades. Nuestro detenimiento en estas localidades viene dado por un interés acumulado, ya que algunas de las hipótesis adelantadas en localidades anteriores, en las de Enciso, Munilla y Arnedillo, se verifican con mayor fortaleza.

El grupo familiar mayor contribuyente, los "Solana", saltan las fronteras del valle y, desde Munilla, extienden sus intereses hasta la capital de la Rioja Alta, Haro. Mientras en Haro se encuentra la "Sociedad de Solana Hermanos" dedicada al comercio de paños (763 rs.), en Munilla encontramos la "Sociedad de Norverto Solana hermanos con artefactos industriales (635 rs.). También de Munilla, la "Sociedad de Vicente Sola-

22. Un cronista local citando a Madoz dice que en Munilla "se cuentan cinco fábricas de paños, siete de batanes, ocho de tintes y más de setenta telares, en que se emplean 150 obreros, además de algunas mujeres y muchachos. Se consume sobre los 420 qq. De lana con la que se construyen 400 piezas de paños de diferentes calidades. Junto a estas fábricas de paños nacieron en Munilla toda clase de fábricas y molinos; en el pueblo se hacía de todo, sus fábricas de chocolates, como tales, fueron las primeras de la Península, y sus molinos harineros de muy buena calidad". HERNÁEZY URRACA (1969), p. 28. 
na hermanos" dice tener artefactos industriales (300 rs.). Por otra parte, Manuel Solana, declara en Munilla como pañero en ambulancia (398 rs.) y en Haro como mercader de ropas hechas (208 rs.).

En Enciso encontramos a uno de los dos mayores contribuyentes, Adrián Alonso con una tienda de telas ( 444 rs.), mientras su hermano Santiago Alonso sigue la fabricación textil con tres cardas, cuatro telares, un batán, una tundosa y cuatro tornos de sesenta husos cada uno ( 287 rs.). Volvemos a citar la complementariedad en las actividades de los miembros de un grupo familiar, tendentes, si las expectativas de descendencia y matrimonio lo permiten, a agrupar y acrecentar el patrimonio familiar, capitalizando en una tercera generación los beneficios de las uniones que representen estas estrategias de reproducción social.

El grupo familiar de "los Quemada" de Enciso, que en 1952 llegarían a celebrar el bicentenario empresarial, en recuerdo del primer Quemada fabricante textil del que se tienen noticia histórica escrita ${ }^{23}$, y que en 1852 tiene como protagonistas a la "Viuda de Quemada y Compañía", fábrica más importante de cuantas aparecen en Enciso, con seis cardas, ocho telares, una tundosa y ocho tornos de 60 husos cada uno (440 rs.); y a Francisco Quemada, también de Enciso, como mercader de lencería, lanería y sedería (429 rs.).

Otro caso familiar de amplio parentesco es el de los "Enciso", que paradójicamente viven en Munilla. De alguno de ellos podemos determinar su parentesco como por ejemplo Esteban Enciso, pañero en ambulancia (398 rs.), su hermano Francisco Javier Enciso con tienda de sedas y lanas ( 411 rs.), y su sobrino Francisco Enciso de Ruiz con un molino de chocolate que sólo muele ocho meses. Otros parientes a los que no hemos logrado situar en el grupo de parentesco, pero que por la realidad de su apellido confirman su adscripción al grupo familiar son, Froylan Enciso con tienda de sedas, lanas y lienzos en ambulancia (398 rs.); Gerónimo Enciso con tienda de sedas y lanas (411 rs.); la sociedad Manuel Enciso e hijos con artefactos industriales (433 rs.); Manuel Enciso y Solana, que también posee artefactos industriales (151 rs.) y Antonio Enciso pañero en ambulancia (398 rs.).

Otros grupos familiares buscan en su estrategia cubrir las actividades industriales en los dos pueblos más representativos del textil riojano en el valle del Cidacos, y en ocasiones incluso en los pueblos próximos a éstos de Enciso y Munilla.

En 1852 participan de actividades industriales textiles "los Giménez". Gregorio Giménez avecindado en Enciso y mercader de paños ambulante ( 429 rs.) y Juan Antonio Giménez, avecindado en Munilla y pañero en ambulancia (398 rs.).

El grupo familiar de los "Aguirre" es el que exhibe un mayor número de individuos dedicados a las actividades industriales o comerciales, estando formado por Eleuterio, Juan, Pío y Rudesindo y los hijos de este último Isidro y Quintín. Por supuesto que son muchos más los individuos familiares que se introducen en el entramado fabril e

23. “(...) los industriales, vecinos de la villa de Enciso, Don Juan Quemada y Don Baltasar Martínez, en su nombre y en representación de numerosos fabricantes de dicho término y de su territorio, en los lugares de Navalsaz, Poyales, Villar, Garranzo, Ruedas, Escurquilla y Valdevigas, cuya producción, el año 1753, supuso más de setenta mil varas de paño fino y doce mil del ordinario." LARRUGA Y BONETA, E.(1792), Madrid.Tomo XXII, pp. 79-97. 
industrial, pero los que cito ahora, son los que en la Matrícula de 1852 aparecen como contribuyentes y por tanto pertenecen a las listas de electores y, por supuesto, de elegidos para la ocupación de cargos políticos de naturaleza local, provincial o nacional.

Eleuterio Aguirre posee tienda de lanas y sedas en Munilla (412 rs.). Juan Aguirre y Pío Aguirre son pañeros en ambulancia de Munilla (398 rs. cada uno). Rudesindo Aguirre tiene en Enciso dos cardas, un torno y un batán (112 rs.), mientras que en la vecina localidad de Munilla posee una tienda de sedas, lanas y confitería (133 rs). Sus hijos continúan la tradición familiar en Munilla, de modo que Isidro declara tienda de sedas y lanas ( 411 rs.), y Quintín tienda de sedas, lanas y confitería (133 rs.). Este último también aparece como arrendatario del ramo del jabón, fundamental en la industria lanera.Así pues, siguiendo con aquella tradición dieciochesca de fabricantesmercaderes, cuando no tratantes de lanas y de forma incipiente lo que luego será una de las especializaciones de esta familia, la fabricación de chocolates, encontramos el entramado familiar industrial extendiéndose por las dos poblaciones y sentando las bases de lo que en la siguiente década aparecerá como un productivo y competitivo valle industrial.

Un caso de diversificación geográfica la ofrecen "los Martínez". Tanto Gregorio como Inocencio Martínez se declaran pañeros en ambulancia en la localidad de Munilla, ambos con la misma cuota (398 rs.), pero Gregorio, además, es mercader de sedas, cintas, etc. en la vecina localidad de Préjano (130 rs.). León Martínez declara dos telares en Munilla (40 rs.) y Pedro Martínez, si bien dice sostener un artefacto industrial en Munilla ( 45 rs.), posiblemente un batán, en Enciso tiene un molino harinero ( 57 rs.) y en el valle vecino, en Jubera, otro molino con una piedra que muele menos de seis meses ( 34 rs.), pero además posee en el lejano pueblo de Igea otro molino maquilero (34 rs), y un trujal de aceite, en un local con dos ruejos (539 rs.). Casi una especialización basada en la diversificación geográfica.

Aunque es posible que no pertenezca al grupo familiar, Tomás Martínez también con un trujal en Murillo de río Leza (286 rs.), pero a pocos kilómetros, en la capital, Logroño, se declara mercader por menor de géneros de lencería, etc (633 rs.), lo cual nos indica que aquellos que se encuentran con capacidad de inversión también encuentran en la escasa estructura industrial o comercial el medio donde depositar sus capitales, sin que por ello deje la tierra de ser el mejor y mayor destino de los capitales de la época ${ }^{24}$, atraídos por los bajos precios de los bienes desamortizados.

En Munilla, se encuentra la Sociedad de Andrés de Torre que por artefactos industriales tiene una cuota de 370 rs., pero también encontramos a Isidoro de Torre, pañero en ambulancia (398 rs.).

También de Munilla son la saga familiar e industrial más representativa de la industria textil y, a comienzos del siglo XX, de la industria zapatillera, nos referimos a "Fernández Hermanos".

"A principios del siglo pasado, los hermanos don Manuel y don Santiago F, vecinos de Munilla, decidieron aprovechar la riqueza ganadera de la región y, por separado, establecieron en dicho pueblo, sendas fábricas de hilados y tejidos de paño de lana. El traslado de las máquinas exigió grandes esfuerzos: a la sazón no existía carre- 
tera.A pesar de las dificultades de entonces, la industria comenzó desenvolviéndose con prosperidad, y los citados señores constituyeron en 1836 la razón social"25.

Los hermanos Santiago y Manuel provienen de Rabanera en el Cameros Viejo, donde su padre Bernabé Fernández Bretón, ganadero trashumante, aunque nacido en Hornillos en 1772, se casó en 1789 con Vicenta Martínez Sáenz, del pueblo de Rabanera de Cameros. Del hecho de que un año no vendiera la lana, se decidió la primera hilatura y también, por el lugar donde se llevó a cabo, el alias de los Fernández, que es "Rabaneras".

En 1852, las vicisitudes de la firma comercial han llevado a que en los libros de cuentas aparezca junto a la firma de Santiago y Manuel Fernández, la de Antonio Enciso y Enciso casado en 1851, con la menor de las hijas de Santiago, María Fernández Enciso. De Antonio Enciso ya habíamos comentado que se declaraba pañero en ambulancia con una cuota de 398 rs., lo que nos permite hablar de una endogamia a la vez que complementariedad de utilidades industriales, la establecida entre suegro y yerno, ya que Fernández Hermanos aparecen como propietarios de artefactos industriales (270 rs.) y como pañeros en ambulancia (398 rs.). Es decir, toda una estrategia matrimonial que busca el recrecimiento de la compañía y su capitalización.

También proceden de Munilla la familia "del Pueyo", donde se encuentran Benito con una prensa (53 rs.); Gaspar con artefactos industriales (227 rs.); León con algún artefacto (35 rs.); Tomás con un molino harinero que muele menos de seis meses (32 rs.) y finalmente José del Pueyo en Logroño que como mercader por menor de géneros de lencería, etc. tiene una cuota de 899 rs.

Otro caso de complementariedad geográfica nos la ofrecen los "Gutiérrez". Manuel Gutiérrez, vecino de Enciso y propietario de dos cardas, seis telares, una prensa, un batán y cuatro tornos de 60 husos (294 rs.), mientras en Munilla se encuentra Juan José Gutiérrez, que por un tinte tiene una cuota de 191 rs.

Hermenegildo Tutor sería el prototipo del moderno fabricante que lleva desde el trato de la materia prima hasta su fabricación y aunque no es dudoso que la mayoría de los fabricantes ajustaran la lana en los agostaderos sorianos cercanos, de Yanguas, San Pedro Manrique, Oncala,Vizmanos y Santa Cruz, sí resulta novedoso el que alguien lo declare, a no ser que el volumen de su trato le llevara a la intermediación para suministro de otros fabricantes. En la localidad de Enciso declara tres cardas, cuatro telares, un batán, una tundosa o tijera y cuatro tornos de 60 husos (286 rs.); y en Munilla como tratante de lanas ( y no es casual que lo sea en el pueblo de más industria fabril), tiene una cuota de 266 rs.

Para finalizar este recorrido por la lista de los principales grupos familiares en las localidades del valle del Cidacos, mencionaremos a "los Ibáñez" de Munilla (Diego, Gabino y Pedro), cada uno de los cuales se dedica a la venta de pañería en ambulancia por la que se les fija una cuota de 398 rs., lo que supone todo un ejemplo de dedicación comercial.

La sociedad "Marrodán hermanos" de Arnedillo, quizás basándose en las necesidades propias de una zona industrial, declaran poseer un taller de recomposición de

25. RIOJA INDUSTRIAL, I945. 
maquinaria (350 rs.), pero además explotan en el mismo Arnedillo, un molino de chocolate que dicen trabajar medio año y por el que se les asigna una cuota fiscal de 233 rs., aspecto que nos confirma que la molienda y en especial la fabricación del chocolate, supone una alternativa ventajosa en la diversificación industrial de la época.

Cuadro V. Mayores contribuyentes del Partido de Nájera

$\begin{array}{llll}\text { Nájera } & \text { Caballero, Román } & \text { Almacenista } & 1016 \\ \text { Nájera } & \text { Duaso, Pedro } & \text { Comercio } & 901 \\ \text { Nájera } & \text { Orus, Andrés } & \text { Comercio } & 772 \\ \text { Nájera } & \text { Berganza, Manuel } & \text { Comercio } & 695 \\ \text { Nájera } & \text { Pérez Forte, Santiago } & \text { Comercio } & 618 \\ \text { Nájera } & \text { Santa María, Millán } & \text { Comercio } & 380 \\ \text { Nájera } & \text { García, Donato } & \text { Comercio } & 283 \\ \text { Nájera } & \text { Pérez, Manuel } & \text { Comercio } & 283 \\ \text { Nájera } & \text { Anguiano, Manuel } & \text { Comercio } & 283 \\ \text { Bobadilla } & \text { Aguirre, Cándido } & \text { Textil } & 270 \\ \text { Nájera } & \text { Martínez, Anastasia } & \text { Trujal } & 257 \\ \text { Nájera } & \text { García Villareal } & \text { Trujal } & 257 \\ \text { Nájera } & \text { Ruiz, Juan Manuel } & \text { Comercio } & 212 \\ \text { Nájera } & \text { Garnica, Pedro } & \text { Comercio } & 212 \\ \text { Canales } & \text { Pablo, Lorenzo } & \text { Tintes } & 206\end{array}$

Fuente: BOPL (1852) y Elaboración Propia

Siguiendo el orden descendente del listado de fabricantes por partido judicial, nos encontramos con el de Nájera, donde junto a Pedroso, en plena decadencia, destaca Canales de la Sierra. Pedroso había descollado en la fabricación manufacturera del XVIII gracias a la lana procedente de los lugares de la Sierra de Cameros, Brieva, Ventosa, las Viniegras, Mansilla, Val de Laguna y Ezcaray, y también algunas veces de la pila de Valvanera, todos ellos descansaderos veraniegos de los rebaños trashumantes segovianos. En 1852 es una localidad dedicada básicamente a la hilatura con cinco fábricas de escasa capacidad, salvo la de Felipe Fernández con seis tornos de sesenta husos y cuatro cardas ( 175 rs.).

En Canales, pese a los diez industriales con cuota fiscal tan sólo cinco poseen lo que hemos denominado estructura fabril de ciclo integral, todos ellos del mismo tenor e igual cuota fiscal (169 rs.). Sus fábricas de paños incluyen dos cardas movidas por agua, 180 husos, dos telares anchos y una tundosa.

Respecto a la existencia de grupos industriales y al margen de las Compañías, detectadas tanto en Canales como en Pedroso, formadas por varias personas, resulta significativo el apellido "Velasco" por la diversificación de sus actividades (industria textil en Canales -169 rs.- y Pedroso -66 rs.-, tenerías en Santo Domingo -153 y 98 rs.-, comercio de paños en Logroño -590 rs.- y Haro -405 rs.- y molino de chocolate en 
Logroño -562 rs.-, aunque nosotros no podemos determinar con certeza una relación de parentesco.

Cuadro VI. Mayores contribuyentes del Partido de Cervera

$\begin{array}{llll}\text { Igea } & \text { Pérez, Inés } & \text { Trujal } & 540 \\ \text { Aguilar } & \text { Lapeña, Calisto } & \text { Comercio } & 429 \\ \text { Igea } & \text { García, Crisanto } & \text { Trujal } & 297 \\ \text { Aguilar } & \text { Guerrero, Saturio } & \text { Trujal } & 286 \\ \text { Aguilar } & \text { Mayor,Andrés } & \text { Textil } & 286 \\ \text { Igea } & \text { Martínez, Pedro } & \text { Trujal } & 284 \\ \text { Cervera } & \text { Ochoa,Basilio } & \text { Trujal } & 282 \\ \text { Cervera } & \text { Sopranís, Miguel } & \text { Trujal } & 282 \\ \text { Cervera } & \text { Alfaro, Teodoro } & \text { Trujal } & 282 \\ \text { Cervera } & \text { Alfaro, Manuel Pascual } & \text { Chocolate } & 282 \\ \text { Cervera } & \text { Martínez, José } & \text { Comercio } & 282 \\ \text { Cornago } & \text { Vallejo, Nicolás } & \text { Trujal } & 258 \\ \text { Cornago } & \text { Calleja, Francisco } & \text { Trujal } & 258 \\ \text { Cornago } & \text { Alfaro, León } & \text { Trujal } & 258 \\ \text { Cervera } & \text { Rubio, Baltasara } & \text { Chocolate } & 254 \\ \text { Cervera } & \text { Ruiz, Cipriano } & \text { Comercio } & 254 \\ \text { Cervera } & \text { González, Alfaro y Miguel } & \text { Textil } & 240 \\ \text { Igea } & \text { Arnedo Díez, José } & \text { Trujal } & 228\end{array}$

Fuente: BOPL (1852) y Elaboración propia

Por último, en el valle del Alhama encontramos los fabricantes de Aguilar y Cervera. En Aguilar se encuentra el fabricante Andrés Mayor ${ }^{26}$ con dos declaraciones de industria; en la primera dice poseer dos telares de los comunes con lanzadera volante de lienzos entrefinos, cuyo ancho excede de una vara castellana (33 rs.) y, en la segunda, 25 telares de ancha tela de vara o menos a 16 reales el par (286 rs.).

D.Antonio Tadeo y Masnata ${ }^{27}$ nos ofrece su particular descripción de la industria linera y cañamera:

"El lino y el cáñamo los cosechan, enrían y agraman los mismos labradores, y sin más preparación pasan al mercado, de donde los toman los sogueros y alpargateros que por regla general son los que se dedican a espadarlos y rastrillarlos, para su inmediato uso o para expenderlos a su vez $y$ proveer al pedido que ocasiona el hilado casero o doméstico.

26. "El hacendado Andrés Mayor que le vemos moverse en la política provincial de los primeros años de las Regencias, cuando aun estaba vigente el Estatuto Real, coaligado a los electores no conformes con el dominio único de la cabeza del Partido Judicial de Cervera”. BERMEJO MARTÍN (1989), p. 114.

27. TADEO Y MASNATA (1876), pp. 47 y 48. 
Una parte de los lienzos ordinarios y aun de clase más fina, que se consumen en muchos pueblos de la provincia, se hace por industriales que poseen un telar común. Es frecuente que el consumidor suministre el hilo recibiendo la tela producida, mediante una cuota en metálico o en especie de la misma primera materia.Además los tejedores por su parte dan al comercio los géneros que elaboran con esas primeras materias o con las que directamente se procuran. En las indicadas condiciones hay establecidos 64 telares.

La confección de alpargatas es otro de los ramos en que se consume la cosecha de materiales textiles de la provincia y aun una porción de los importados.

Pero las industrias linera y cañamera en grande escala, están representadas por las fábricas de Aguilar y Cervera del Río Alhama, en el primero de cuyos pueblos, hay una de hilados y tejidos de lino, y en el segundo, dos de géneros de cáñamo. Estos establecimientos importan en su mayor parte las hilazas del extranjero especialmente de los mercados de Inglaterra y producen, la primera, mantelerias y lienzos de diferentes clases y las otras dos, telas para sacos y lonas dignas de mencionarse por su perfección."

A pesar de que esta descripción pertenece a una realidad 24 años más tarde, sirve para situar el tipo de fabricación llevada a cabo por los fabricantes de 1852; es decir, Aguilar en el entorno del lino y Cervera en la del cáñamo con dos fabricantes, pese a que en la relación aparezcan cuatro del siguiente modo: $1^{\circ}$ ) los Sres. González, Alfaro y Miguel declarando una máquina de filatura impulsada por agua con 9 bancas: una torcedera, una carda cilíndrica y 6 preparaciones que sólo hilan con 400 husos (240 rs.); $2^{\circ}$ ) los también Sres. González, Alfaro y Miguel que declaran una máquina o artefacto de lana con 4 tornos de hilar y 4 cardas cilindricas que solamente hilan o tienen en acción de hilar 280 husos (147 rs.); $3^{\circ}$ ) Hilario González y Compañía, por 5 telares de lienzos ordinarios para margas (34 rs.), y $4^{\circ}$ ) los Sres. Escudero y Compañía, por otros 5 telares de lienzos ordinarios para margas, etc. (34 rs.).

Respecto de esta última, sabemos que Cervera poseía en 1792 la Fábrica de iniciativa real, de lonas, vitres e hilazas, además de 25 telares para el tejido de lienzos caseros, pero $\mathrm{Madoz}^{28}$, al realizar el cómputo de las cuatro fábricas existentes, comenta que:

"las 3 son muy pequeñas, y la principal establecida en 1798 con ayuda del Gobierno y a propuesta de D.Mariano de Traggia, marqués de Palacios, se cerró en 1808; pero después reunidos los hijos de los primitivos fundadores, se dedicaron a trabajar para los buques mercantes bajo la sociedad que hoy existe, titulada Escudero y Compañía. Son tales los adelantos hechos por dicha sociedad en esta clase de manufacturas, que están declaradas por el Gobierno como las primeras o de mejor calidad de cuantas se trabajan en España, fabricando sobre 600 piezas todos los años".

Con relación a Hilario González y Compañía, tenemos noticias sobre el origen de su capital ${ }^{29}$, de procedencia harinera, y sus inversiones ${ }^{30}$ en la fabricación de tejidos de lana y cáñamo en Cervera, una vez que en 1848 reflotara la antigua Real Fábrica de lonas para la Armada. La fábrica disponía de 13.000 husos y 12 telares mecánicos que consumían 20.000 arrobas de cáñamo y producían más de 5.000 piezas.

28. MADOZ (1846) (1985), p. 79.

29. MORENO LÁZARO (1990), pp. 105 y 106.

30. GARCIA COLMENARES (1996). 
No sabemos si ambos fabricantes (Escudero e Hilario González), trabajaban en la misma instalación fabril, pero las informaciones contrastadas parecen aseverarlo.

También hemos rastreado en la Matrícula de 1852, los apellidos "González,Alfaro y Miguel", poseedores de las otras instalaciones fabriles, y hemos encontrado a María González, mercader de sedas, cintas, hilos en madeja, etc. (184 rs.), y a Nicasio González, mercader de sedas, cintas, hilos en madejas u ovillos, fajas, etc. en una misma tienda (141 rs.). También en Cervera se encuentra D.Manuel Pascual Alfaro, mercader de chocolate, sedas, cintas, hilos en madejas u ovillos, fajas, etc., en una misma tienda (282 rs.); a Teodoro Alfaro, con un molino de aceite de una viga (282 rs.), y un molino maquilero de represa o cauce con una piedra que muele más de seis meses ( $57 \mathrm{rs}$.); a Fermín Alfaro que posee dos molinos maquileros de represa o cauce con una piedra cada uno que muelen más de seis meses (113 rs.) y por último, en la localidad vecina de Cornago a León Alfaro con una viga de aceite (258 rs.) y un molino de represa y cauce que muele sólo seis meses ( 32 rs.). Por último, Antonio Miguel y Félix Miguel, cada uno con una cuota de 127 rs., como mercaderes de sedas, cintas, hilos en madejas u ovillos, fajas, etc. en una misma tienda. Es decir, aun sin comprobar la posible relación de parentesco de estos fabricantes con los contribuyentes que acabamos de citar, nos encontramos con que en una misma localidad, la diversificación de los capitales industriales o comerciales entre las escasas industrias o comercios, es una constante en los grupos adscritos a un linaje; en la mayoría de los casos complementan la industria textil con la molienda, el trujal o las lonjas de chocolate.Asimismo, la comercialización de los paños o los tejidos es otra constante, bien en tiendas o a través de la venta ambulante. Por último, destacar que unos mismos apellidos copan las mayores cuotas contributivas de cada localidad que hemos citado.

Una última cualidad de los contribuyentes que conviene destacar en la localidad de Cervera del Río Alhama es la existencia de dos tiendas de alpargatas mas otros cinco que se declaran alpargateros con tienda, lo que nos da ref́lejo de la importancia del cáñamo y de su producción alpargatera que aun hoy en las postrimerías del siglo XX sigue siendo una de las principales formas de adquirir un ingreso principal o secundario por la mayoría de las familias cerveranas.

Finalmente, reconocer que los 24 contribuyentes arrieros con una o varias caballerías, no es un hecho casual, en una localidad fronteriza con las provincia exenta de Navarra y con las de Zaragoza y Soria.

Cuadro VII. La industria textil riojana: utillaje (1852-1861-1876)

\begin{tabular}{|c|c|c|c|c|c|c|c|c|c|c|c|c|}
\hline \multirow{5}{*}{$\begin{array}{l}\text { Ezcaray } \\
\text { Valgañón } \\
\text { S3O.DOMINGo }\end{array}$} & \multicolumn{3}{|c|}{ CARDAS } & \multicolumn{3}{|c|}{ HUSOS } & \multicolumn{3}{|c|}{ TELARES } & \multicolumn{3}{|c|}{ BATANES } \\
\hline & 1852 & 1861 & 1876 & 1852 & 1861 & 1876 & 1852 & 1861 & 1876 & 1852 & 1861 & 1876 \\
\hline & 46 & 40 & & 4140 & 4900 & & 77 & 180 & & 6 & 13 & \\
\hline & & 11 & & & 1050 & & 2 & 25 & & 1 & & \\
\hline & 48 & 51 & 19 & 4140 & 5950 & 3660 & 81 & 205 & 75 & 10 & 13 & 7 \\
\hline Canales & 10 & 14 & & 720 & 2500 & & 6 & 172 & & 2 & 6 & \\
\hline Pedroso & 11 & 10 & & 120 & 2950 & & 4 & & & 1 & & \\
\hline NAJERA & 23 & 24 & 9 & 1020 & 5450 & 909 & 18 & 172 & 10 & 4 & 6 & $?$ \\
\hline Ortigosa & 10 & 10 & & & 3100 & & 4 & & & & & \\
\hline Torrecilla & 14 & $=$ & & 2280 & & & & 60 & & 4 & 3 & \\
\hline
\end{tabular}




\begin{tabular}{|l|ccc|ccc|ccc|ccc|}
\hline & \multicolumn{3}{|c|}{ CARDAS } & \multicolumn{3}{c|}{ HUSOS } & \multicolumn{3}{c|}{ TELARES } & \multicolumn{3}{c|}{ BATANES } \\
\cline { 2 - 12 } & 1852 & 1861 & 1876 & 1852 & 1861 & 1876 & 1852 & 1861 & 1876 & 1852 & 1861 & 1876 \\
\cline { 2 - 5 } & 9 & 3 & & 720 & 2090 & & 3 & 29 & & 2 & 2 & \\
Rabanera & 2 & 5 & & & & & 4 & 16 & & 1 & & \\
Soto & & 8 & & 1380 & 5100 & & 25 & 42 & & 7 & 6 & \\
TORRECILLA & 35 & 31 & 29 & 4380 & 10290 & 2908 & 38 & 147 & 60 & 16 & 11 & 8 \\
Arnedillo & 4 & 19 & & 180 & 4100 & & & 80 & & 3 & & \\
Enciso & 16 & 14 & & 1260 & 2500 & & 22 & 172 & & 5 & 6 & \\
Munilla & & 32 & & & 4100 & 5 & 200 & & & 10 & \\
ARNEDO & 20 & 65 & 58 & 1440 & 10700 & 4750 & 37 & 452 & 106 & 9 & 16 & 18 \\
Aguilar & & & & & & & 27 & 82 & & & & \\
Cervera & 5 & 24 & & 680 & 4000 & & 10 & 200 & & & 5 & \\
CERVERA & 5 & 24 & & 680 & 4000 & 37 & 282 & 79 & & 6 & \\
TOTAL PARTIDOS & 131 & 195 & 115 & 11660 & 36390 & 12218 & 211 & 1258 & 330 & 39 & 52 & 34 \\
\hline
\end{tabular}

Fuente: BOPL (1852); Giménez Guited (1861); Delgado y Masnata (1876) y Elaboración propia.

\begin{tabular}{|c|c|c|c|c|c|c|c|c|c|c|c|c|}
\hline & \multicolumn{3}{|c|}{ PERCHAS } & \multicolumn{3}{|c|}{ TUNDOSAS } & \multicolumn{3}{|c|}{ PRENSAS } & \multicolumn{3}{|c|}{ TINTES } \\
\hline & 1852 & 1861 & 1876 & 1852 & 1861 & 1876 & 1852 & 1861 & 1876 & 1852 & 1861 & 1876 \\
\hline Ezcaray & & & & 22 & 30 & & 3 & & & 5 & & \\
\hline Valgañón & & & & & & & & & & 1 & & \\
\hline STO.DOMINGO & & & 17 & 22 & 30 & 15 & 3 & & 12 & 6 & & 6 \\
\hline Canales & & 11 & & 3 & 16 & & 1 & & & & & \\
\hline Pedroso & & & & 2 & & & & & & 1 & 2 & \\
\hline NAJERA & & 11 & 4 & 5 & 16 & 4 & 1 & & & 1 & 2 & 1 \\
\hline Ortigosa & & & & 5 & & & 2 & & & & & \\
\hline Torrecilla & & & & 5 & 11 & & 3 & & & 5 & 1 & \\
\hline Villoslada & & & & & & & & & & & 2 & \\
\hline Rabanera & & & & & 6 & & & & & & & \\
\hline Soto & & & & 20 & & & 2 & 5 & & 7 & 7 & \\
\hline TORRECILLA & & & 5 & 30 & 17 & 13 & 7 & 5 & 5 & 12 & 10 & 6 \\
\hline Arnedillo & & & & & 21 & & & & & & & \\
\hline Enciso & & 11 & & 3 & 16 & & 1 & & & & 3 & \\
\hline Munilla & & & & & 38 & & 1 & & & 1 & & \\
\hline ARNEDO & & 11 & 19 & 3 & 75 & 17 & 2 & & 7 & 1 & 3 & 12 \\
\hline Aguilar & & & & & & & & & & & & \\
\hline Cervera & & & & 9 & 19 & & & & & & & \\
\hline CERVERA & & & & 9 & 19 & & & & 1 & & & \\
\hline TOTAL PARTIDOS & & 22 & 45 & 69 & 157 & 49 & 13 & 5 & 25 & 20 & 15 & 25 \\
\hline
\end{tabular}

Fuente: BOPL (1852); Giménez Guited (1861); Delgado y Masnata (1876) y Elaboración propia.

La primera observación que debemos hacer a los cuadros comparativos entre las series de datos extraídos de la Matrícula de Contribución Industrial de1852, la Guía Fabril de Giménez Guited de 1862 y la Memoria de Industrias Derivadas de Tadeo y Masnata de 1876, es la escasa fiabilidad que nos ofrece los datos aportados por Giménez Guited, dado el salto cuantitativo que se aprecia entre estos y los de la Matrícula de 1852 y entre estos y los de la Memoria de 1876. No es posible que La Rioja sumara a mitad de siglo 11.660 husos y diez años después se convirtieran en 36.390 para que quince años más tarde bajen hasta los 12.218. Ni resulta creíble que los 211 tela- 
res de 1852 se conviertan diez años después en 1.258 para bajar a los quince años hasta los 330. Parecen saltos demasiado radicales, pese a que en su conjunto puedan ofrecer tendencias de crecimiento y desindustrialización como en definitiva así fué.

En cuanto a las series de datos extraídas de la Matrícula de Contribución de 1852 , está claro, tal y como apreciábamos al principio, que los datos aportados por los contribuyentes son dudosamente útiles para el reconocimiento de la estructura de la propiedad o de los capitales, pero en definitiva lo que andamos buscando es relacionar y comparar entre series estadísticas que nos permitan expresar tendencias e indicios sobre lo que fué la realidad fabril. Un trabajo posterior que indague en los protocolos notariales, sobre todo en los inventarios post-mortem, como fuente comparativa de información, acabaría con las dudas acerca de la veracidad de cuantas series estadísticas se extraen de las listas de contribución industrial.

Volviendo al objeto de nuestro interés, el utillaje fabril en 1852, se cumple lo dicho sobre número de fábricas por partido judicial.Así destaca el de Torrecilla por el número de husos, batanes, tundosas, prensas y tintes debidos a sus fábricas de Torrecilla y Soto, cabeceras industriales de sus respectivos valles de los Ríos Iregua y Leza. Le sigue en esta particular escala descendente el partido judicial de Santo Domingo por el número de cardas y telares, debidos principalmente a la localidad de Ezcaray. Debería estar el de Arnedo en tercer lugar si no nos faltaran los datos de aquellos fabricantes de Munilla que sólo expresan artefactos industriales sin especificarlos. De hecho, el partido de Arnedo es el único que crece en las décadas siguientes mientras que el resto decae de forma generalizada; tan sólo en el partido de Torrecilla hay un leve mantenimiento en el número de cardas, batanes, prensas y tintes, pero se debe principalmente al crecimiento de las existentes en Ortigosa, mientras la localidad de Torrecilla verá desaparecer su liderato en el valle. Ezcaray mantendrá su estructura productiva gracias al impulso mecanizador de la primera mitad de siglo, pese algunas imperfecciones ${ }^{31}$ que unidas a las estrategias de inversión de capitales en otras áreas productivas y lejos de la localidad, le llevarán a la pérdida de la hegemonía en la fabricación textil riojana, relevo que tomarán las localidades del valle del Cidacos, que con la distancia debida, plantearon su desarrollo al modo que observaron los líderes nacionales de Sabadell y Terrasa.

\section{MeCaNización de la INDUSTRIA TEXTIL RIOJANa A MEDIADOS DEL SIGLO XIX}

En 1852 conocemos algunas de las innovaciones técnicas existentes en las fábricas textiles del valle del Oja, como la prensa hidráulica de la Viuda de Francisco Bicheroa (en realidad Francisco Bicheraux, asociado con Pedro Alemán como intermediarios en la importación de maquinaria textil). Los dos tornos movidos por agua para retorcer seda de 60 anillos de la Real Fábrica de sedas y las dos cardas cilíndricas de Tomás Boulandie (emparentado con la familia de maquinistas de origen belga, Lamberto y Nicolás Dumoulin), citadas en Ezcaray. En Ojacastro se citan dos cardas cilíndricas para lana de la Viuda de Carlos Sáenz. Precisamente fue para la fábrica de

31. OJEDA SAN MIGUEL (1993), p. 93. 
Carlos Sáenz que los Dumoulin construyeron en 1831 una máquina transversal o tundidora y entre 1834 y 1835 las dos cardas cilíndricas ${ }^{32}$.

Ya en el valle del Najerilla y en Canales, encontramos a sus fabricantes con todas sus cardas movidas por agua, citando también el batán de rueda o mazo y la prensa sencilla. Ojeda San Miguel ${ }^{33}$ relata que Lamberto Dumoulin realizó para una compañía pañera de Canales, en 1830, una máquina de cardar e hilar lana, compuesta de una emborradora con cardas, una letera con los mismos, un diablo, un torno de mechar, cuatro tornos para fino y dos aspas con el correaje correspondiente y necesario. También para el fabricante de Canales, Benito González, realizó tres años después una máquina "Transversal" con una percha de 18 palmares.

En el valle del Iregua (Camero Nuevo), en la localidad de Torrecilla, se citan máquinas de hilar con dos cardas y seis hilanderos, con dos cardas y cinco hilanderos y con dos cardas y cuatro hilanderos; los batanes son de una pila. Precisamente para el fabricante de Torrecilla, Santiago Martínez Pinillos, los importadores Alemán y Bicheraux, harán traer en 1840 un juego completo de máquinas de cardar e hilar lana a un precio de cuarenta y cuatro mil reales ${ }^{34}$. En la localidad de Villoslada, que posee un lavadero de lanas que se ocupa dos meses o menos, existen tres fábricas de paños que poseen tres cardas, que son una letera y dos emborradoras movidas por agua. Los tornos son movidos a mano como los telares, mientras los batanes son el uno con dos mazos y el otro con un mazo.

Ya en el valle del Leza (Cameros Viejo), en la localidad de Soto, sus fabricantes distinguen la posesión de bancas y tundidoras; los batanes son de rueda y mazo. Dumoulin, junto al maquinista Marcelino Campo, montó en Soto una máquina de lustrar paños o prensa lustrosa en el año 1843.

En el valle del Cidacos, sabemos que en Arnedillo un fabricante posee cardas cilíndricas, así como un industrial que manifiesta poseer un taller de recomposición de maquinaria. De Munilla no citan sus artefactos industriales; los batanes, son de mazo o de rueda y mazo.

En el valle del Alhama, en Aguilar, encontramos la cita de dos telares de lienzos entrefinos con lanzadera volante; y en Cervera la existencia de una máquina de filatura impulsada por agua con 9 bancas: una torcedera, una carda cilíndrica y 6 preparaciones de hilar. También una máquina de lana con cuatro tornos de hilar y cuatro cardas cilindricas.

Esto es todo lo que se puede extraer de la Matrícula de 1852 como utillaje innovador, siendo tan escasas las máquinas hidráulicas (prensa, tornos y sobretodo cardas cilíndricas), que podemos hacer nuestro y extensivo a toda la provincia de Logroño, las conclusiones que Ojeda San Miguel $^{35}$ señala sobre Ezcaray:

32. "una para emborrar y otra para emprimar, cuatro tornos para bilar fino de sesenta busos cada uno, un torno de mechar, compuesto de cuarenta busos, un Diablo de aumento susceptible de dar la labor bien y para tres juegos, dos aspas con la medida a la catalana, cuatro esmeriles de cuatro caras para gobierno de dichas máquinas, una llave inglesa de un pie cumplido y las demás de costumbre para las aspas..." OJEDA SAN MIGUEL (1989), p. 37.

33. OJEDA SAN MIGUEL (1989), p. 38.

34. OJEDA SAN MIGUEL (1989), p. 40.

35. OJEDA SAN MIGUEL (1989), p. 42. 
"La primera mitad del siglo XIX para la pañería del Alto Oja más exactamente habría que calificarla como una época de imperfecta mecanización. En este sentido todos los documentos notariales utilizados hasta ahora ponen de manifiesto que la industrialización de esta pañería sólo tuvo lugar en las labores de cardado, hilado y en las finales de tundido y apresto. Ni una sola escritura señala la compra o construcción de algún tipo de telar más moderno que los clásicos manuales. Es sumamente significativo que a la altura de 1856 la provincia entonces de Logroño, donde el peso de la comarca de Ezcaray era muy importante, englobara el 26,2 por ciento de los husos manuales y el 4,8 de los mecánicos a nivel nacional en el proceso de la hilatura, así como el 5,5 por ciento de los telares manuales y tan sólo el 0,5 de los mecánicos en las operaciones de tisaje ${ }^{36 ”}$.

Cuadro VIII. Aparatos de hilatura y tisaje en la industria textil riojana (1852-1900)

\begin{tabular}{|l|ccc|cccc|}
\hline & \multicolumn{3}{|c|}{ HUSOS } & \multicolumn{4}{c|}{ TELARES } \\
\cline { 2 - 8 } & MANUALES & MECANICOS & TOTALES & MANUALES & MECANICOS & JACQUARD & TOTALES \\
\cline { 2 - 8 } 1852 & 11660 & & 11660 & 211 & & & 211 \\
1856 & 14306 & 5100 & 19406 & 302 & 2 & & 304 \\
1863 & 4150 & 17980 & 22130 & 342 & & & 342 \\
1876 & 6308 & 5910 & 12218 & 270 & 23 & 37 & 330 \\
1879 & 465 & 6720 & 7185 & 230 & & 39 & 269 \\
1900 & 160 & 4068 & 4228 & 105 & 17 & $40^{*}$ & 162 \\
\hline
\end{tabular}

Fuente: BOPL (1852); ECI 1856-1879-* (García Colmenares); 1863-1900 (Gallego y otros); 1876 (Delgado y Masnata) y Elaboración Propia.

Tal y como han apreciado numerosos investigadores, el proceso de mecanización en la entonces provincia de Logroño, se llevó a cabo en los procesos iniciales y finales de la industria textil lanera, olvidando o al menos actuando con tardanza y a destiempo en las operaciones de tisaje. Si observamos la columna de husos, el proceso de mecanización fué lento y sólo se mantuvo hasta las postrimerías del siglo, en que comenzó un nuevo periodo de cambio en la producción y concentración de las empresas fabriles en algunos grupos industriales de Cameros y el Valle del Cidacos, pero ya lejos de la importancia cuantitativa que a nivel nacional sostuvo desde el siglo XVIII.

Resulta significativo que sea al final de la década de los setenta cuando se produzca la caída definitiva de los husos manuales, pues ello nos indica la pervivencia de los modos artesanales en connivencia con la moderna fabricación hasta bien avanzado la segunda mitad del siglo, lo cual hace notar la resistencia habida tanto por parte de las hiladoras, rueca y huso en mano, las cuales encontraban un medio complementario a sus ingresos, como por los fabricantes, que aceptaban unos productos, también complementarios a los de la hilatura mecanizada. También podríamos explicarnos este desarrollo lento en la mecanización de la industria fabril, a causa de las estrategias de capitalización e inversión, que necesariamente se tomaban a medio y largo plazo, ya

36. NADAL, J. y MALUQUER, J. (1985), pp. 79 y 80. 
que estaban basadas en los compromisos matrimoniales que se adoptaban para con los hijos de los fabricantes. El acceso al capital inversor, allá donde la estructura financiera se encontraba en un grado inicial, escasamente vinculado a la inversión industrial, sólo podía conseguirse mediante estrategias familiares de acumulación de capital, que permitieran en definitiva la necesaria inversión en utillaje y maquinaria. Cualquier otra referencia a contextos más dinámicos de inversión, es una pura quimera en la realidad burguesa riojana ${ }^{37}$ de la segunda mitad del XIX.

Sobre dichas estrategias encontramos numerosos documentos notariales donde se escrituran las dotes por esponsales, o bien a través de los llamados consejos paternos, por los que se admiten determinados matrimonios en los que se advierte de las cuantías o propiedades que acompañan al contrayente, $o$ bien mediante cartas de pago y recibos de dote, todo ello y principalmente a partir de la década de los sesenta.

En cuanto a la observación de la columna sobre evolución del número de telares, hacemos una reflexión parecida. De este modo es preciso considerar el crecimiento en el número de telares manuales hasta la década de los setenta, en que comenzará su lenta desaparición, y de los que curiosamente hoy sólo existen vestigios en el museo textil de Terrasa y los aun en activo como producción artesanal, en la villa de Ezcaray. En cuanto a los telares mecánicos ${ }^{38}$, poco sabemos salvo su aparición en la ECI de 1856 (el primer telar mecánico que se introduce en Terrasa ${ }^{39}$ es en 1864); y los ocho que cita Tadeo y Masnata en 1876, ya que los otros quince que suma la columna, son telares mecánicos dedicados al lino y el cáñamo en las fábriças del Alhama. Curiosamente, son los telares con jacquard, los que se aprecian en mayor número, también en la Memoria de 1876 (22 de lana y 15 de lino y cáñamo), por lo que deducimos que en décadas anteriores hicieron su aparición en la industria textil riojana. Sobre tal aspecto, Diego Ochagavía ${ }^{40}$ nos ilustra con una cita sobre la obra manuscrita, compuesta de 115 páginas, que se titula "Tratado Teórico-práctico de la Fabricación de Tejidos" y que fué escrita en el año 1865 por el fabricante de Munilla D.Federico Enciso. En la introducción del Tratado se dice:

"El objeto de esta obrita es cubrir la necesidad que hay de un sistema teóricopráctico dedicado exclusivamente a la fabricación de lanerías.

De unos 20 años a esta parte, la industria lanera ha tenido un desarrollo extraordinario y así como antes de este tiempo, se puede decir que la totalidad de estos tejidos eran llanos, o con muy poca variación, hoy es todo lo contrario; obligada por el capricho de la moda, se vió en la necesidad de recurrir a los telares con máquina de Jacquard, y por lo tanto de emprender los estudios teórico-prácticos, para llevar acabo esta nueva fabricación.

En los años que llevamos de explotación en esta industria son pocos los fabricantes y directores, que por medio de la teoria, han sabido conquistar un puesto honroso en esta difícil carrera, pero afortunadamente éstos, cargados de fé y con un activo trabajo, no sólo han dado vida a sus pueblos, sino que sus géneros pueden competir con las principales fábricas extranjeras; pero desgraciadamente los hombres de vastos conocimientos no son los más, y a los más, es a quien dedico esta obri-

37. BERMEJO MARTÍN, F. "La Banca Riojana".Trabajo inédito.

38. Parejo cita 17 telares mecánicos en la ECI de 1900. PAREJO BARRANCO (1989), p. 52.

39. NADAL, J. (1992), p. 123.

40. OCHAGAVÍA FERNÁNDEZ (1957), pp. 258, 259 y 260. 
ta, que por su sencillez, claridad, y más que todo por abrazar como queda dicho exclusivamente la fabricación lanera, les será más fácil de comprender, a los que a este estudio se dediquen".

Si hacemos caso de este fabricante, desde aproximadamente 1845 , la industria ha avanzado hasta el punto de competir en el mercado con "la fabricación extranjera". También nos cuenta que hoy -1865-, son mayoría los fabricantes que han recurrido al jacquard (todo lo contrario a antes de 1845), aunque debido a sus escasos conocimientos teóricos, han tenido que recurrir a la fe y al trabajo activo para abrirse un hueco en el mercado, y es por ello que escribe esta obrita teórico-práctica.

Igualmente, la introducción del jacquard ${ }^{41}$ en las fábricas de la provincia de Logroño, podemos estimar que pudo tener efecto entre 1845 y la década de los cincuenta, fechas muy próximas a las que cita $\mathrm{Nadal}^{42}$ para Terrasa, donde el jacquard fue introducido por Galí y Codoñet en1845.

Antes de 1845 no sólo estaba descuidada la modernización de la maquinaria textil, salvo entre algunos industriales ya apuntados, sino que lo que supuso una mayor competencia en el mercado productor, la utilización de nuevas energías, sufrió un retraso considerable.A este fin sirve la cita de $\mathrm{Madoz}^{43}$, que para esas fechas comenta que:

"La colocación de las Aduanas en las fronteras de las cuatro provincias exentas (Vascongadas y Navarra) y la nivelación con las restantes del litoral y fronteras de la Península en cuanto a leyes restrictivas del comercio, dejaron ver al logroñés reducido a la permuta de frutos por frutos y a la expedición a las provincias lindantes de los productos de la industria, con la desventaja de tener que competir en aquellas lonjas con género de tan buena calidad, o tal vez mejor, pero de más cómodo precio, por el menor costo que originaba a sus fabricantes la elaboración con maquinaria y empleo del vapor de agua como agente motor, mejora que todavía se hallaba un poco descuidada en las fábricas de tejidos de la provincia de Logroño".

Así pues, el uso de vapor ${ }^{44}$, acaso por los usos del agua repartida entre molinos, batanes y otros artefactos, así como por el número de fabricantes y locales que disponían de las mismas aguas ${ }^{45}$, apenas tuvo desarrollo como energía alternativa. Todavía en 1893, un descriptor ${ }^{46}$ de la sociedad riojana de su tiempo nos cuenta que:

"Aparte de que las industrias no tienen en las poblaciones reducidas todos los elementos para la instalación de máquinas en el grado de los centros populosos, el

41. "Jacquard dio a conocer su famoso telar en 1804, tras mejorar a sus predecesores Basile Bouchon, Falcon y Vaucanson".

42. NADAL, J. (1992), p. 123.

43. MADOZ (1846) (1985), p. 120.

44. Según la Memoria de Tadeo y Masnata (1876) sólo en el partido de Arnedo se encuentran las dos únicas fábricas textiles con motor de vapor, frente a las 21 con motor hidráulico, las 9 del de Nájera, 16 del de Santo Domingo y 25 del de Torrecilla. Es decir, el vapor brilla por su ausencia. Entre los 20 molinos y fábricas de chocolate, sólo uno dispone de motores de vapor. Por último, entre las de lino y cáñamo, existen tres con motores hidráulicos.

45. "Las aguas finas y seguras durante todo el año, por encontrarse los ríos cerca de sus nacimientos, prestaron a Munilla lo que las tierras le negaban. Con el agua podían ponerse en movimiento las máquinas, escaldar lanas y tintar sin peligro de correr los colores”. HERNÁEZY URRACA (1969), p. 28.

46. JORDÁ Y PADRO (1893), p. 115. 
carbón tampoco se halla al precio que en éstos, y ello motiva que se aproveche con vivísimo interés la fuerza motriz promovida por las aguas fluviales utilizando saltos y cataratas, construyendo esclusas, o encauzando y derivando las corrientes, según los accidentes y desniveles del terreno; y aunque los generadores de vapor han hecho al sistema hidráulico una incesante y rudísima campaña, no por esto ha pasado la oportunidad de sacar partido de aquel potente, sencillo y antiquísimo recurso.

La multiplicación de la potencia o salto por la longitud del trayecto recorrido, la del radio de la rueda, amplitud de la paleta de aplicación de los receptores en la forma de ruedas, turbinas u otras máquinas, son circunstancias que no olvida jamás el ingeniero hábil y experimentado, ni pasan tampoco desapercibidas para el que tenga que valerse de cualquier motor por una corriente de agua"

No debemos extrañarnos tras la lectura de estas líneas, que tras la rueda hidráulica, ésta se viera sustituida por las turbinas o motores de eje vertical, siendo el siguiente paso en el proceso de obtención de energía, la electricidad, ya que la fuerza hidráulica de que se disponía, a base de pequeños caudales, estaba mediatizada por el estiaje que la paralizaba cerca de medio año.Algunas de las fábricas (los Sevillas), disponían de dos saltos de agua dentro del edificio con la que obtenían energía de siete a ocho meses (de invierno a primavera), y en tiempos de sequía utilizaban como energía el gas pobre producido mediante antracita. Claro está, a sabiendas de que la electricidad no tuvo presencia industrial en el valle del Cidacos, hasta principios del siglo XX.

Por otra parte, si a esto sumamos las necesidades hulleras y carboníferas en una región sin desarrollo minero y el descuido en las comunicaciones terrestres para su transporte desde las zonas productoras, nos explicaremos en parte, otras de las causas que motivaron el desenlace de la producción textil a finales de siglo. Calvo Palacios ${ }^{47}$ establece el despegue industrial de la provincia de Logroño a partir de 1868, con la consolidación de las industrias de la madera y los grupos empresariales textiles que al darse cuenta de la problemática de sus industrias tratan de introducir en ellas maquinaria moderna. Constata que las inversiones extranjeras se dieron fundamentalmente en minas, ya que por la Ley de Bases de 1868 se concedían las minas a perpetuidad mediante el pago de un canon al Estado. Así puede observarse que en 1870 se inicia la explotación de minas de cobre en Canales; en 1884 en Ventrosa; en las minas de lignito de Turruncún y Préjano se nota un mayor optimismo a partir del 1868, etc.

Volviendo a la existencia de husos mecánicos y telares mecánicos o con jacquard, incluso pese a su crecimiento en la década de los setenta, la industria textil riojana, perderá su segundo puesto en el mercado productor de tejidos de lana en beneficio de las provincias de Alicante, Salamanca o Valencia. Un contemporáneo ${ }^{48}$ nos saca de dudas acerca del tipo de tejidos que se producían en aquel momento (1876), y que las estadísticas nos dicen que es el de máximo crecimiento en la modernización del parque de maquinaria de la industria textil riojana:

"La industria lanera toma principalmente sus primcras materias de la ganadería dé país y de las provincias limírofes Cuenta con fábricas de hifados y tejidos, que producen paños terciopelos de lana y bayetas entre los cuales son notables los paños en colores cafe y negro, clase entefina, propios para canas que gozan de un

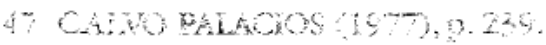


mercado bastante extenso y sostienen la competencia, dentro y fuera de la provincia, con los de su clase de otras procedencias, tanto por la calidad del género, como por lo cómodo del precio a que pueden darse, a causa de la facilidad que tienen los fabricantes para adquirir la lana y para proporcionarse buenos y numerosos operarios a precios módicos. En este ramo se distingue el pueblo de Ezcaray.

Los paños de Enciso, clase ordinaria y colores café y negro, alcanzan gran aceptación entre la clase obrera, por su mucha duración y baratura, y compiten igualmente con sus similares de otros puntos.

Los terciopelos de lana de Munilla (...), se producen en abundancia y hacen competencia a los de Alcoy.

No han alcanzado tanto crédito y perfección los paños para trajes, que se elaboran a imitación de los de Sabadell y Tarrasa, con los cuales no pueden competir y mucho menos con los extranjeros, pues no hay en el país lanas de igual calidad. (...).

En contraposición, la industria ha decaído de una manera notable en Soto de Cameros, de donde amenaza desaparecer sino se rehace su crédito y obtiene mayor exportación.

En cuanto a las bayetas, y con especialidad las de Hortigosa, tiene bastante salida para todos los puntos del Reino".

Así pues, la descripción es lo suficientemente significativa, como para aventurar otras hipótesis sobre las causas de la decadencia de la industria provincial. En primer lugar, el tipo de fabricación basado en la proximidad del mercado de lanas y sus precios competitivos, por lo que en un momento de caída de la cabaña ganadera o de subida de sus precios el paño finalista incrementaría sus precios, dejando de ser competitivo con los de su clase, procedentes de otras provincias. De Ezcaray advierte que se mantiene por la facilidad que tiene en el suministro de lanas (no olvidemos el camino de laneros desde Mansilla -en el Najerilla- hasta Ezcaray), y los bajos salarios de los numerosos operarios de que dispone, condiciones que a la postre yugularán su producción textil. De hecho, un riojano finisecular, Jordá y Padró ${ }^{49}$, constata esta decadencia lanar y sus consecuencias:

"(...), y si a ésto se añade que la tala insensata de los bosques, que en algunas regiones llega a verdadero despoblado, deja sin abrigo al ganado, no es difícil convencerse de que encareciéndose la lana como materia prima, haya decaído este comercio, y con él las industrias derivadas textiles y tintóreas, que ya por si no pueden competir con las de igual clase, que disponen de mayores elementos como fuerza motriz, puesto que la única ventaja para nosotros depende de la mayor baratura en la materia prima de elaboración, que rarísima vez se alcanza sin detrimento".

En segundo lugar, la clientela a la que va destinado el producto (paños entrefinos y ordinarios color café y negro), nos dice que es la clase obrera cuyo poder adquisitivo está sometido a las vicisitudes del desarrollo económico y social del último cuarto de siglo, sobre el que no nos extenderemos en este momento, aunque a propósito he recogido un refrán, dictado en Munilla, sumamente expresivo:"Todos nacen en cueros y después se van vistiendo; unos de paño pardo y otros de terciopelo".

Tan sólo los terciopelos de Munilla mantienen la competencia de Alcoy, pero no así la de los núcleos catalanes cuya calidad está fuera de toda duda y cuya clientela es

49. JORDA Y PADRO (1893), p. 8. 
principalmente la burguesía, que gusta del traje de paño catalán. Por último Ortigosa, sostiene la tradicional fabricación de bayetas, compartiendo mercado con los restos de la otrora fábrica popular ${ }^{50}$.

Tampoco las demás provincias podrán mantener por largo tiempo la competencia con la provincia de Barcelona y sus localidades de Sabadell y Terrasa, siendo la provincia castellana, la primera que se deslizará por la pendiente de la decadencia industrial, al tiempo que le ocurrirá a la riojana, aunque la reconversión industrial que tuvo lugar a principios del XX, conseguirá sostener durante décadas, algunas de estas localidades con un rico pasado manufacturero y fabril de la industria textil.

\section{CONCLUSIONES}

En primer lugar debemos subrayar una vez más la importancia de utilizar nuevas fuentes estadísticas como la que ahora hemos desbrozado, con el fin de contribuir a un mejor conocimiento de la historiografia regional y nacional. En nuestro caso hemos hecho las advertencias oportunas sobre la fiabilidad de los datos presentados (indicativos de tendencias tras su comparación con otras series estadísticas), así como sobre el interés para el conocimiento de las élites locales, entendiendo por tales, aquellos grupos sociales que tienen capacidad de decidir sobre el uso de los factores productivos.

Del análisis de la Matrícula de Contribución Industrial de 1852, podemos concluir que el periodo que se extiende entre 1845 y 1880 , es un tiempo en el que se llevó con desigual ritmo, la renovación de utillaje y la mecanización de la industria textil fabril.

En este mismo periodo se dará un proceso de concentración de la industria rural dispersa en localidades que iniciarán o continuarán la renovación tecnológica de su utillaje, lo que desembocará en la transformación en industrias de carácter fabril completo o de ciclo integral (aproximadamente unas 60 para todo el territorio de la provincia de Logroño), que simultanearán su actividad y la completarán con industrias de fase (principalmente en las localidades del valle del Oja), y con la del artesanado y la manufactura rural dispersa, ya en plena regresión. Empresas familiares de distinta dimensión con una estructura productiva flexible en la que se combina fábrica y trabajo doméstico, empresas de ciclo integral e industrias de fase, todo según sean las estrategias hereditarias de los fabricantes de principios de siglo.

El avance hacia la concentración industrial es lento y no se producirá realmente hasta el último cuarto de siglo, fruto de las estrategias matrimoniales y de reproduc-

50. "Hacia el año 1840 se crearon dos fábricas en el pueblo, utilizando las aguas del río Alberco para mover sus artefactos, pero la poca energía motriz que las aguas del río proporcionaban obligó a sus dueños a desplazarse fuera del casco urbano para aprovechar el aumento del caudal del río, por la afluencia de algunos manantiales, y en el valle, al Este de Ortigosa, se instalaron hasta seis fábricas, que durante más de treinta años emplearon numerosos brazos, produciendo gran cantidad de paños que eran vendidos en diversas regiones de España, especialmente Galicia.

La disminución y casi desaparición del ganado trashumante, por un lado, y el progreso y adelanto de la industria pañera en varios sitios de la Península, por otro, hicieron que el paño hecho en Ortigosa (...), disminuyese su consumo en forma tal, que la mayor parte de las fábricas hubieron de cerrarse, lo que también ocurrió en Torrecilla, Villoslada y Ezcaray". MARTÍNEZ OLMEDO (1946), pp. 110 y 111. 
ción social de los primeros fabricantes, origen de los grupos familiares industriales y comerciales, las cuales, necesariamente se tomaban a medio y largo plazo.

La carencia de grandes capitales, por su diversificación entre la estructura comercial e industrial de la época (así como las inversiones en desamortizaciones), llevará a un proceso lento en la renovación de utillaje, centrándose principalmente en las fases más costosas por el elevado número de mano de obra, como son las de emborrado, cardado e hilado, y las de acabado (batanado, teñido, perchado, tundido y prensa). La mecanización, por tanto, será de grado medio.

El universo en que se mueve la burguesía industrial riojana de mediados del XIX, está delimitado por la diversificación de sus actividades productivas (textil, molinería y chocolate), complementado con las actividades comerciales, a través de la profesión de mercader en tiendas, lonjas, almacenes y venta ambulante, de paños, ropas hechas, sedas, cintas, confitería, chocolate, etc.

En las zonas del Cidacos y Alhama, el trujal aparece como un instrumento más de diversificación industrial. En el Alhama se encuentra la industria linera y cañamera, donde también encontramos grupos familiares diversificando sus actividades con la molienda, el trujal, las lonjas de chocolate y la comercialización de tejidos. En esta zona es donde se dan un gran número de alpargateros, así como de arrieros dado el carácter limítrofe provincial de estas localidades.

La venta ambulante se encuentra relacionada con la tradicional arriería y comercio, que desde Galicia hasta Andalucía se mantuvo en el siglo XVIII, en la obligada parada invernal de la actividad ganadera trashumante. También es de carácter tradicional el entramado familiar industrial de fabricantes-mercaderes y tratantes de lanas; de ahí el dinamismo de estos grupos al establecer redes comerciales en los principales centros mercantiles.

Las causas de la decadencia de la industria textil en el último cuarto de siglo hay que determinarlas a partir de algunas de las tendencias detectadas con anterioridad. Las principales serían:

$\left.1^{\circ}\right)$ La lenta e imperfecta mecanización. La hilatura artesana y manual pervivió con la fabril hasta finales de los setenta. La desaparición lenta de los telares manuales nunca conllevó un crecimiento del de los mecánicos, pese a su pronta aparición. Sólo los jacquard tuvieron un cierto desarrollo desde mediados de siglo.

$2^{\circ}$ ) El retraso considerable en la adopción de energías alternativas a la hidráulica. Escasa implantación del vapor. Paradas estacionales por el estiaje de los ríos y escaso y tardío desarrollo minero y de comunicaciones.

$3^{\circ}$ ) La fabricación industrial basada en la proximidad de los mercados de la lana y los bajos salarios, determinará los costes de los productos en competencia con los de otras regiones en los mercados tradicionales. Las diferentes coyunturas ahogarán su inicial competitividad.

$\left.4^{\circ}\right)$ Los productos industriales, cuyos destinatarios finales serán las clases populares y obreras con un poder adquisitivo determinado también por las diferentes coyunturas sociales y económicas. 


\section{BIBLIOGRAFÍA CITADA}

ALONSO CASTROVIEJO, J.J. (1991)

Problemática agraria y solución burguesa. Logroño 1750-1833. Logroño.

BENAUL BERENGUER, J.M. (1995)

"Cambio tecnológico y estructura industrial. Los inicios del sistema de fábrica en la industria pañera catalana, 1815-1835". Revista de Historia Económica ${ }^{\circ} 2$.

BERMEJO MARTÍN, F.

La banca riojana en el siglo XIX.Trabajo inédito.

BERMEJO MARTÍN, F. y DELGADO IDARRETA, J.M.(1989)

La Diputación Provincial de La Rioja. Logroño.

CALVO PALACIOS, J.L. (1977)

Los Cameros. Logroño

CONGOST, R. (1983)

"Las listas de los mayores contribuyentes de 1875". Agricultura y Sociedad n²7.

DELGADO Y MASNATA,A.T. (1876)

Memoria sobre el estado de la Agricultura e Industrias Derivadas en la Provincia de Logroño. Logroño.

GALLEGO, D. y otros (1992)

"Transformaciones económicas en el Valle del Ebro (1800-1936"), en Serrano Sanz (Dir), Estructura Económica del Valle del Ebro, Madrid.

GARCÍA COLMENARES, P. (1996)

"Crisis de la artesanía textil tradicional e industrialización en Castilla y León".

GARCÍA COLMENARES, P. (1996)

"Desindustrialización e industrialización del textil castellano y leonés, 1800-1930".

GIMÉNEZ GUITED, (1862)

Estadística industrial de España. Madrid.

HERNÁEZ Y URRACA, M. J. (1969)

Munilla, pueblo ilustre. Logroño.

JORDA Y PADRO, J. (1893)

Logroño Económico. Logroño.

LARRUGA Y BONETA, E. (1792)

Memorias Políticas y Económicas sobre los Frutos, Comercio, Fábricas y Minas de España. Madrid.

MARTÍNEZ CUADRADO, M. (1974)

La burguesía conservadora (1874-1931). Madrid.

MARTÍNEZ OLMEDO, L. (1946)

La villa de Ortigosa de Cameros. Madrid.

MADOZ, P. (1846)

Diccionario Geográfico-Estadístico-Histórico de España y sus posesiones de Ultramar. Rioja. (Facsímil. Logroño, 1985). 
MOLL, I.,ALBERTI, A. y MOREY, A. (1993)

"El repartimiento individual de la Contribución Territorial, Industrial y Mercantil de Baleares en 1852: una fuente para el estudio de estructuras socioeconómicas y distribución social de recursos". Noticiario de Historia Agraria $\mathrm{n}^{\circ} 5$.

MORENO FERNÁNDEZ, J.R. (1994)

El monte público en La Rioja durante los siglos XVIII y XIX; aproximación a la desarticulación del régimen comunal. Logroño.

MORENO LÁZARO, J. (1990)

La industria harinera en Castilla y León (1841-1864). Valladolid.

NADAL, J. (1985)

Un siglo de industrialización en España. Madrid.

NADAL, J. (1992)

Moler, tejer, fundir. Estudios de bistoria industrial. Barcelona.

OCHAGAVÍA FERNÁNDEZ, D. (1957)

Historia Textil Riojana. Logroño.

OJEDA SAN MIGUEL, R. (1989)

Notas sobre la mecanización de la pañería de Ezcaray en la primera mitad del siglo $X I X$. Logroño.

OJEDA SAN MIGUEL, R. (1993)

La fallida industrialización de una comarca riojana: el alto valle del Oja. Logroño.

PAREJO BARRANCO, A. (1989)

La industria lanera española en la segunda mitad del siglo XIX. Málaga.

Rioja industrial (1945). Logroño. 